\title{
Aerosol optical properties derived from the DRAGON-NE Asia campaign, and implications for a single-channel algorithm to retrieve aerosol optical depth in spring from Meteorological Imager (MI) on-board the Communication, Ocean, and Meteorological Satellite (COMS)
}

\author{
M. Kim ${ }^{1}$, J. Kim ${ }^{1}$, U. Jeong ${ }^{1}$, W. Kim ${ }^{1}$, H. Hong ${ }^{2}$, B. Holben ${ }^{3}$, T. F. Eck ${ }^{3,4}$, J. H. Lim ${ }^{5}$, C. K. Song ${ }^{5}$, S. Lee ${ }^{5, \text { a }}$, and \\ C.-Y. Chung 6 \\ ${ }^{1}$ Department of Atmosphere Sciences/IEAA BK 21 plus, Yonsei University, Seoul, Korea \\ ${ }^{2}$ Department of Spatial Information Engineering, Pukyong National University, Busan, Korea \\ ${ }^{3}$ NASA Goddard Space Flight Center, Greenbelt, MD, USA \\ ${ }^{4}$ Universities Space Research Association, Columbia, MD, USA \\ ${ }^{5}$ National Institute of Environmental Research (NIER), Inchon, Korea \\ ${ }^{6}$ National Meteorological Satellite Center, Gwanghyewon-myeon, Jincheon-gun, Chungcheongbuk-do, Korea \\ anow at: Asia Center for Air Pollution Research (ACAP), Niigata-shi, Japan
}

Correspondence to: J. Kim (jkim2@yonsei.ac.kr)

Received: 11 March 2015 - Published in Atmos. Chem. Phys. Discuss.: 14 April 2015

Revised: 5 January 2016 - Accepted: 18 January 2016 - Published: 16 February 2016

\begin{abstract}
An aerosol model optimized for northeast Asia is updated with the inversion data from the Distributed Regional Aerosol Gridded Observation Networks (DRAGON)northeast (NE) Asia campaign which was conducted during spring from March to May 2012. This updated aerosol model was then applied to a single visible channel algorithm to retrieve aerosol optical depth (AOD) from a Meteorological Imager (MI) on-board the geostationary meteorological satellite, Communication, Ocean, and Meteorological Satellite (COMS). This model plays an important role in retrieving accurate AOD from a single visible channel measurement. For the single-channel retrieval, sensitivity tests showed that perturbations by $4 \%(0.926 \pm 0.04)$ in the assumed single scattering albedo (SSA) can result in the retrieval error in AOD by over $20 \%$. Since the measured reflectance at the top of the atmosphere depends on both AOD and SSA, the overestimation of assumed SSA in the aerosol model leads to an underestimation of AOD. Based on the AErosol RObotic NETwork (AERONET) inversion data sets obtained over East Asia before 2011, seasonally analyzed aerosol optical properties (AOPs) were categorized by SSAs at $675 \mathrm{~nm}$
\end{abstract}

of $0.92 \pm 0.035$ for spring (March, April, and May). After the DRAGON-NE Asia campaign in 2012, the SSA during spring showed a slight increase to $0.93 \pm 0.035$. In terms of the volume size distribution, the mode radius of coarse particles was increased from $2.08 \pm 0.40$ to $2.14 \pm 0.40$. While the original aerosol model consists of volume size distribution and refractive indices obtained before 2011, the new model is constructed by using a total data set after the DRAGON-NE Asia campaign. The large volume of data in high spatial resolution from this intensive campaign can be used to improve the representative aerosol model for East Asia. Accordingly, the new AOD data sets retrieved from a single-channel algorithm, which uses a precalculated look-up table (LUT) with the new aerosol model, show an improved correlation with the measured AOD during the DRAGONNE Asia campaign. The correlation between the new AOD and AERONET value shows a regression slope of 1.00 , while the comparison of the original AOD data retrieved using the original aerosol model shows a slope of 1.08 . The change of $y$-offset is not significant, and the correlation coefficients for the comparisons of the original and new AOD are 0.87 
and 0.85 , respectively. The tendency of the original aerosol model to overestimate the retrieved AOD is significantly improved by using the SSA values in addition to size distribution and refractive index obtained using the new model.

\section{Introduction}

An understanding of global aerosol distribution and its optical characteristics is important, not only for predictions related to climate change, but also for monitoring the effects of changing air quality on human health. It is widely accepted that aerosol has both direct and indirect effects on the Earth radiation budget (IPCC, 2013). Aerosols are also linked to respiratory illnesses (e.g., Pope and Dockery, 2006) and meningitis epidemics (e.g., Deroubaix et al., 2013). Since the global aerosol distribution shows high spatial and temporal variability, many studies have developed aerosol retrieval algorithms utilizing both low Earth orbit satellite measurements (Hsu et al., 2004; Kim et al., 2007; Torres et al., 2007; Kahn et al., 2010; Lyapustin et al., 2011b; von HoyningenHuene et al., 2011; Wong et al., 2010; Bevan et al., 2012; Sayer et al., 2012; Levy et al., 2013) and geostationary orbit (GEO) satellite measurements (Knapp et al., 2002, 2005; Wang et al., 2003; Urm and Sohn, 2005; Yoon et al., 2007; Kim et al., 2008; Lee et al., 2010; Zhang et al., 2011; Kim et al., 2014). These studies have typically adopted an inversion approach, using a precalculated look-up table (LUT) based on assumed aerosol optical properties (AOPs) to retrieve aerosol information from the measured visible reflectance at the top of the atmosphere. In this method, the accurate estimation of surface reflectance and assumption of optimized aerosol optical type are key to retrieve accurate aerosol information. The surface information was taken into account by using a single-view algorithm based on a multi-channel algorithm with certain assumptions (e.g., Levy et al., 2007b), or by using multiple-view algorithms for the multi-angle Advanced Along-Track Scanning Radiometer (AATSR) (Grey et al., 2006) or the Polarization and Directionality of the Earth's Reflectances (POLDER) sensor (Waquet et al., 2009) measurements. Under conditions of low aerosol optical depth (AOD), the estimation of surface reflectance is most crucial to retrieve accurate AOD, while assumptions about the type of aerosol are more significant for cases with higher AOD. A variation in single scattering albedo (SSA) of $\pm 3 \%$ (based on a reference value of 0.90 ) results in a $10 \%$ error for moderate AOD $(\tau=0.5$ at $0.67 \mu \mathrm{m})$ and a $32 \%$ error for large AODs ( $\tau=1.5$ ) (Zhang et al., 2001). Lee et al. (2012) used a triaxial ellipsoidal database of dust (Yang et al., 2007) and inversion data from the AErosol RObotic NETwork (AERONET) to greatly improve the AOD retrieved using the MODIS dark target algorithm with regards to its Pearson coefficient (from 0.92 to 0.93 ), regression slope (from 0.85 to 0.99 ), and the percentage of data within an expected error bound (from 62 to $64 \%)$.
Ground-based measurements are essential to the construction of a well-defined aerosol model to calculate LUT. Aerosol observations from ground-based sun/sky radiometer measurements, such as the AERONET, provide accurate global and local AOPs, including AOD and particle characteristics (Duvobik et al., 2000; Holben et al., 1998). Numerous aerosol models for satellite aerosol algorithms have been based on the AERONET data sets (e.g., Sayer et al., 2014), and these models can be further improved by using AOPs obtained from intensive field campaigns in high spatial resolution (e.g., Huebert et al., 2003; Nakajima et al., 2007). Recently, the Distributed Regional Aerosol Gridded Observation Networks (DRAGON)northeast (NE) Asia 2012 campaign over South Korea and Japan, during spring from March to May 2012, provided a valuable insight into the characteristics of aerosol over metropolitan areas (http://aeronet.gsfc.nasa.gov/new web/DRAGON-Asia_2012_Japan_South_Korea.html). The campaign studied aerosol characteristics over known polluted areas affected by diverse aerosol sources such as urban pollutants and transported dust. In addition, the high spatial resolution data from the campaign were used to validate the satellite aerosol algorithms covering the same region.

To investigate the role of the mesoscale network of ground-based aerosol measurements in the satellite-based AOD retrieval, an aerosol retrieval algorithm based on the inversion method is tested in this study. By using a singlevisible measurement of Meteorological Imager (MI) onboard the Communication, Ocean, and Meteorological Satellite (COMS), an AOD retrieval algorithm was developed by Kim et al. (2014), and it provides valuable results regarding aerosol distribution and transport. Since the algorithm cannot detect temporal and spatial variation of AOPs, the single type of assumed, optimized aerosol model was used as in previous studies (e.g., Knapp et al., 2002; Yoon, 2006; Yoon et al., 2007; Wang et al., 2003). In this regard, the representative aerosol model is important to reduce the uncertainty in AOD retrieval. Here, the aerosol model from a previous study (Kim et al., 2014) is newly analyzed by using an extended data set after the DRAGON-NE Asia campaign. The campaign, which focuses on the monitoring of aerosol properties over Korea and Japan, can provide details of aerosol distribution, and contribute to accumulating the data set. The new aerosol model applied to the single-channel algorithm, and the retrieved AODs, are compared with directly measured values from the DRAGON-NE Asia campaign.

The single-channel algorithm used in this study is similar in nature to that described by Kim et al. (2014), which improved the basic single-channel algorithm by applying the critical reflectance method and background AOD (BAOD) correction. To consider the importance of the aerosol type selection, the algorithm applied the critical reflectance method (Fraser and Kaufman, 1985) to determine the SSA for each measured scene over urban areas. Meanwhile, the BAOD, representing the persistent concentration of aerosol, even in 
the clearest air conditions, was estimated by finding the minimum AOD among the long-term measurements. Since the algorithm estimated surface reflectance based on the minimum reflectance method, underestimation or neglect of the BAOD results in the overestimation of the surface reflectance, and thus leads to the underestimation of AOD (Knapp et al., 2002; Yoon, 2006). The correction for BAOD to the surface reflectance showed significant effects in Kim et al. (2014), and is also considered here, whereas the critical reflectance method is not adopted to evaluate the effects of assumed aerosol properties on the AOD retrieval.

Though the accuracy of AOD retrieved from the singlechannel algorithm is limited because of the limitation in type detection, the products obtained from GEO measurements have an advantage of continuous monitoring of aerosol emission and transport from source regions in high temporal resolution. The continuous monitoring is expected to improve the capability of predicting ambient aerosol properties (e.g., Saide et al., 2014; Park et al., 2014).

The data sets used in this study are summarized in Sect. 2, and details of the single-channel algorithm and its results are described in Sect. 3. Modifications to the aerosol model using data from the DRAGON-NE Asia campaign, and their effects on subsequent retrievals, are outlined in Sect. 4.

\section{Data}

\subsection{DRAGON-NE Asia campaign}

AERONET, a network of globally distributed ground-based sun photometers, is widely used to understand global AOPs and to validate satellite-based aerosol products. The AERONET sun photometer measurements of direct solar radiation provide accurate measurements of AOD $(\sim 0.01$ in the visible and near-infrared and $\sim 0.02$ in the ultraviolet) under cloud-free conditions (Eck et al., 1999; Holben et al., 1998, 2001), and sky radiance measurements in an almucantar scenario can be inverted to calculate AOPs such as size distribution, single scattering albedo, phase functions, and the complex index of refraction (Dubovik and King, 2000; Dubovik et al., 2000, 2002).

During the DRAGON-NE Asia campaign in 2012, 20 Cimel sun-sky radiometer instruments were deployed in Seoul, as well as in eastern and western parts of South Korea. In Japan, about 20 instruments were deployed in Osaka, west Japan, and Fukushima valley. The distribution of DRAGON Korea and Japan sites is shown in Fig. 1, along with the number of AOD data provided in level 2.0 (cloud-screened and quality-assured; Smirnov et al., 2000) direct products during the campaign. These deployed sun photometers provided the high spatial-resolution information to address characteristics of mega city aerosol. Figure 2 shows the average and standard deviation for each AOD $(500 \mathrm{~nm})$ and Ångström exponent (AE, $440-870 \mathrm{~nm}$ ) measured during the campaign. In

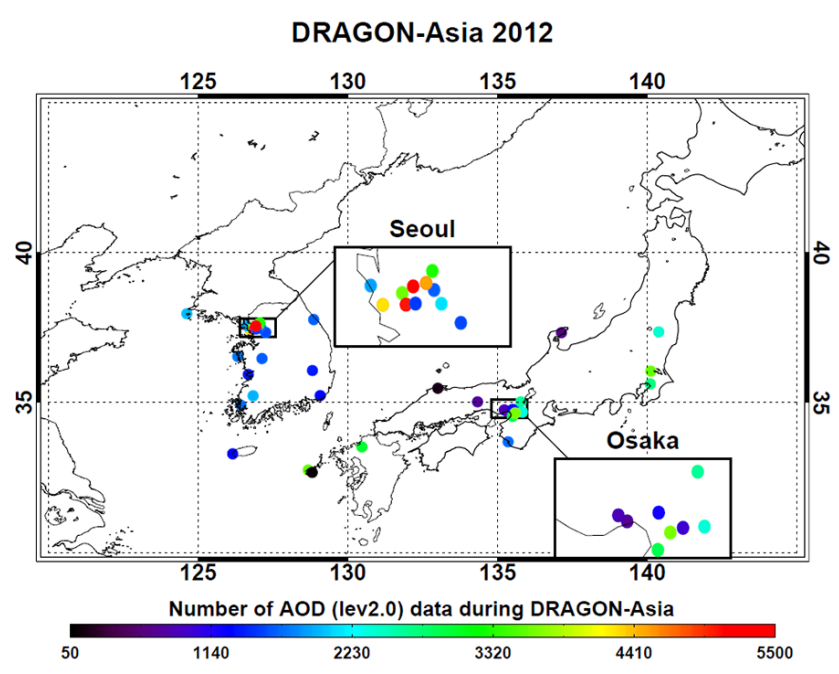

Figure 1. Location and number of data points of the AERONET sun photometers deployed during DRAGON-NE Asia 2012. The color of each symbol represents the number of AOD (level 2.0) data points measured for the campaign.

Fig. 2a, the average AOD ranged between 0.23 and 0.52 , and showed a decreasing behavior towards the southeast. The maximum value of 0.52 was found at two sites in Fukue $\left(128.68^{\circ} \mathrm{E}, 32.75^{\circ} \mathrm{N}\right)$ and Sanggye $\left(127.07^{\circ} \mathrm{E}, 37.66^{\circ} \mathrm{N}\right)$, while a minimum value of 0.23 was found at Kohriyama site $\left(140.38^{\circ} \mathrm{E}, 37.36^{\circ} \mathrm{N}\right)$. In terms of local average, the mean AOD of 0.43 in Seoul was higher than the value of 0.30 in Osaka. Similarly, the standard deviation of AOD in Fig. $2 b$ was low in the eastern part of Korea. While the standard deviation varied between 0.22 and 0.31 in Seoul, the values in Japan were between 0.11 and 0.16 . The regional difference is also calculated in terms of AE in Fig. 2c. The respective average AE of 1.20 and 1.27 in Seoul and Osaka represents that the particle size in Seoul is larger than that in Osaka, in general. The spatial distributions of AOD and AE can be related closely with transport of aerosol in East Asia during winter and spring (Park et al., 2014).

In this study, the extensive AERONET inversion data (level 2.0 daily products) over East Asia $\left(20-50^{\circ} \mathrm{N}, 95\right.$ $145^{\circ} \mathrm{E}$ ) were used to analyze optimized AOPs; the retrieved volume size distribution and complex refractive indices are utilized to compute the spectral SSA. Duvobik et al. (2000) recommended that the quality of refractive index and SSA becomes reliable when the AOD $(440 \mathrm{~nm})$ is higher than 0.4 and the solar zenith angle is higher than $45^{\circ}$. To avoid insufficient data points for a low AOD case, the daily averaged product was applied. Level 2.0 AOD data sets measured for the DRAGON-NE Asia 2012 campaign with more than 50 data points were used to validate the retrieval results. The AERONET sites used, including the campaign sites, are listed in Table 1, along with the period of the inversion products. The campaign sites are numbered, and sites indicated 

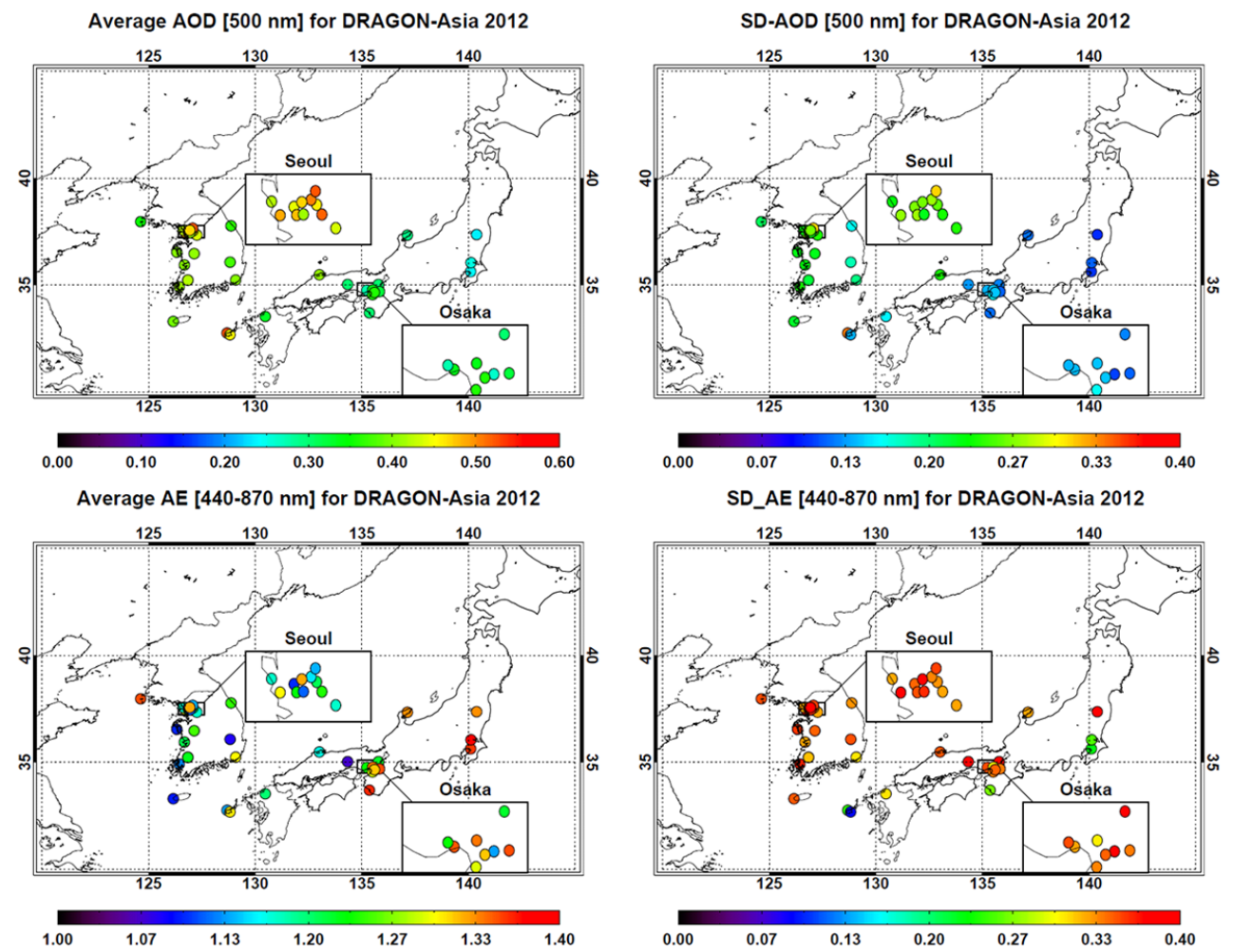

Figure 2. The (a, c) average and (b, d) standard deviation $(1 \sigma)$ of (a, b) AOD at $500 \mathrm{~nm}$ and (c, d) Ångström exponent between 440 and $870 \mathrm{~nm}$ during DRAGON-NE Asia 2012 campaign for each site.

in bold represent the validation sites selected randomly to test the consistency of the retrieval accuracy. The inversion products obtained at those validation sites were not applied to analyze the aerosol model, but direct AOD products were used to validate the algorithm. While a total of 12126 inversion data sets from 1999 to 2012 were compiled, 84091 AOD data sets were applied from the campaign at 39 sites in the spring of 2012.

\subsection{COMS Meteorological Imager}

A multi-purpose geostationary satellite, COMS, designed to orbit at a longitude of $128.2^{\circ} \mathrm{E}$, was launched on 27 June 2010 by the Korean government. The satellite performs meteorological and ocean monitoring by using the MI and Geostationary Ocean Color Imager (GOCI) instruments. The MI measures the single visible reflectance ( 0.55 $0.80 \mu \mathrm{m})$ at a $1 \mathrm{~km}$ spatial resolution, and the brightness temperature (BT) at four infrared (IR) wavelengths at a $4 \mathrm{~km}$ spatial and $30 \mathrm{~min}$ temporal resolution. The four IR channels cover spectral ranges of 10.3-11.3 (IR1), 11.5-12.5 (IR2), 6.5-7.0 (IR3), and 3.5-4.0 $\mu \mathrm{m}$ (IR4). The MI can cover a full disk from its equatorial position at $128.2^{\circ} \mathrm{E}$, though this study focuses mainly on images from East Asia. The MI measurements from the single visible and four IR channels are applied to retrieve land and ocean surface temperature, incoming and outgoing radiance, and atmospheric variables including aerosol, cloud properties, precipitable water, and upper tropospheric humidity. The level 2.0 products can be obtained from the National Meteorological Satellite Center (http://nmsc.kma.go.kr/html/homepage/ko/main.do) of Korea.

\subsection{MODIS AOD}

To estimate the BAOD distribution over East Asia over a long period, an AOD product from the Moderate Resolution Imaging Spectroradiometer (MODIS) (Collection 5.1; MYD04_Lv2.0) was used at $10 \times 10 \mathrm{~km}^{2}$ resolution. The AOD at $550 \mathrm{~nm}$ from a dark target algorithm (Levy et al., 2007b, 2010; Remer et al., 2005) was interpolated onto a grid of $0.25^{\circ} \times 0.25^{\circ}$ to find the minimum value for each area. Considering spatial variation of BAOD, the MODIS product was applied to cover a wider area over the long term, although satellite measurements have larger uncertainty than the ground-based measurements. The expected error in the AOD product is $\pm(0.05+15 \%)$, and over $66 \%$ of the retrieved AODs from the MODIS algorithm lie within the error range, with a correlation coefficient of 0.9 (Levy et al., 2010). Despite the seasonal variation of atmospheric conditions over northeast Asia, the seasonal variation of the BAOD was not considered because of insufficient data points for winter and 
Table 1. Summary of AERONET sites used in this study. The "Period" column represents the retrieval period of the daily inversion product (level 2.0), and the longitude (long., ${ }^{\circ} \mathrm{E}$ ) and latitude (lat., ${ }^{\circ} \mathrm{N}$ ) show the location for each site. The number before the site name lists the sites operated for the DRAGON-Asia campaign, where "D" is the initial of the campaign. The numbers are linked to Tables 3, 4, and Fig. 10. The type of character categorizes the inversion data set into the "original", "new", and "excepted" groups. While the "original" group is compiled from the inversion data sets obtained before 2011 at sites in italic type, the "new" group consists of the total data set excluding the "excepted" group shown in bold type.

\begin{tabular}{|c|c|c|c|c|c|c|c|}
\hline Site & Long. & Lat. & Period & Site & Long. & Lat. & Period \\
\hline (1) Baengnyeong & 124.63 & 37.97 & 2010-2013 & (36) Osaka & 135.59 & 34.65 & $\underline{2001}-\underline{2013}$ \\
\hline (2) Chiba_University & 140.1 & 35.63 & 2011-2012 & $\overline{\text { (37) Seoul_SNU }}$ & 126.95 & 37.46 & $2000-2013$ \\
\hline (3) D_Anmyeon & 126.33 & 36.54 & DRAGON2012* & (38) Shirahama & 135.36 & 33.69 & $\underline{2000-2013}$ \\
\hline (4) D_Bokjeong & 127.13 & 37.46 & DRAGON2012 & (39) Yonsei_University & 126.93 & $\overline{37.56}$ & $\overline{2011}-\overline{2013}$ \\
\hline (5) D_Fukue & 128.68 & 32.75 & DRAGON2012 & Anmyon & 126.33 & 36.54 & 1999-2007 \\
\hline (6) D_Fukue_2 & 128.82 & 32.67 & DRAGON2012 & Bac_Giang & 106.23 & 21.29 & 2003-2009 \\
\hline (7) D_Fukuoka & 130.48 & 33.52 & DRAGON2012 & Bach_Long_Vy & 107.73 & 20.13 & 2010-2011 \\
\hline (8) D_GangneungWNU & 128.87 & 37.77 & DRAGON2012 & Beijing & 116.38 & 39.98 & $\underline{2001-2013}$ \\
\hline (9) D_Guwol & 126.72 & 37.45 & DRAGON2012 & $\overline{\text { Chen-Kung_Univ }}$ & 120.22 & $\underline{23}$ & $\overline{2002}-2012$ \\
\hline (10) D_Hankuk_UFS & 127.27 & 37.34 & DRAGON2012 & $\overline{\text { Dongsha_Island }}$ & 116.73 & $2 \overline{0.7}$ & $\overline{2004}-\overline{2013}$ \\
\hline (11) D_Kobe & 135.29 & 34.72 & DRAGON2012 & $\overline{E P A-N C} U$ & 121.19 & 24.97 & $\overline{2006}-\overline{2013}$ \\
\hline (12) D_Kohriyama & 140.38 & 37.36 & DRAGON2012 & $\overline{\text { Hangzhou-ZFU }}$ & 119.73 & 30.26 & $\overline{2007}-\overline{2007}$ \\
\hline (13) D_Kongju_NU & 127.14 & 36.47 & DRAGON2012 & Hefei & 117.16 & 31.91 & 2005-2008 \\
\hline (14) D_Konkuk_Univ & 127.08 & 37.54 & DRAGON2012 & Hong_Kong_Hok_Tsui & 14.26 & 22.21 & $\underline{2007-2010}$ \\
\hline (15) D_Korea_Univ & 127.03 & 37.58 & DRAGON2012 & $\overline{\text { Hong_Kong_PolyU }}$ & $\overline{114.18}$ & 22.3 & $\overline{2005}-\overline{2013}$ \\
\hline (16) D_Kunsan_NU & 126.68 & 35.94 & DRAGON2012 & Inner_ & 115.95 & $\overline{42.68}$ & $\overline{2001}-2001$ \\
\hline (17) D_Kyoto & 135.78 & 35.03 & DRAGON2012 & $\overline{\text { Jingtai }} \overline{ }$ & 104.1 & $\overline{37.33}$ & $\overline{2008}-\overline{2008}$ \\
\hline (18) D_Kyungil_Univ & 128.82 & 36.07 & DRAGON2012 & Lanzhou_City & 103.85 & 36.05 & 2009-2010 \\
\hline (19) D_Matsue & 133.01 & 35.48 & DRAGON2012 & Liangning & 122.7 & 41.51 & 2005-2005 \\
\hline (20) D_Mokpo_NU & 126.44 & 34.91 & DRAGON2012 & Luang_Namtha & 101.42 & 20.93 & 2012-2014 \\
\hline (21) D_Mt_Ikoma & 135.68 & 34.68 & DRAGON2012 & Lulin & 120.87 & 23.47 & $\underline{2007-2014}$ \\
\hline (22) D_Mt_Rokko & 135.23 & 34.76 & DRAGON2012 & $\overline{\text { Minqin }}$ & 102.96 & $\overline{38.61}$ & $\overline{2010}-\overline{2010}$ \\
\hline (23) D_NIER & 126.64 & 37.57 & DRAGON2012 & NGHIA_DO & 105.8 & 21.05 & 2010-2013 \\
\hline (24) D_Nara & 135.83 & 34.69 & DRAGON2012 & PKU_PEK & 116.18 & 39.59 & 2006-2008 \\
\hline (25) D_Nishi-Harima & 134.34 & 35.03 & DRAGON2012 & SACŌL & 104.14 & 35.95 & 2006-2012 \\
\hline (26) D_Osaka-north & 135.51 & 34.77 & DRAGON2012 & Shouxian & 116.78 & 32.56 & 2008-2008 \\
\hline (27) D_Osaka-south & 135.5 & 34.54 & DRAGON2012 & Taichung & 120.49 & 24.11 & $\underline{2005-2005}$ \\
\hline (28) D_Pusan_NU & 129.08 & 35.24 & DRAGON2012 & $\overline{\text { Taihu }}$ & 120.22 & $\overline{31.42}$ & $\overline{2005}-\overline{2012}$ \\
\hline (29) D_Sanggye & 127.07 & 37.66 & DRAGON2012 & Taipei_CWB & $\underline{121.5}$ & 25.03 & $\underline{2002-2013}$ \\
\hline (30) D_Sinjeong & 126.86 & 37.52 & DRAGON2012 & Ussuriysk & $\overline{132.16}$ & 43.7 & $\overline{2004}-\overline{2013}$ \\
\hline (31) D_Soha & 126.89 & 37.45 & DRAGON2012 & $\overline{\text { Xianghe }}$ & $\overline{116.96}$ & $\overline{39.75}$ & $\overline{2001}-\overline{2012}$ \\
\hline (32) D_Tsukuba & 140.12 & 36.05 & DRAGON2012 & Xinglong & 117.58 & 40.4 & 2006-2012 \\
\hline (33) Gosan_SNU & 126.16 & 33.29 & $\underline{2001}-\underline{2013}$ & Yufa_PEK & 116.18 & 39.31 & 2006-2006 \\
\hline (34) Gwangju_GIST & 126.84 & 35.23 & $\overline{2004}-\overline{2012}$ & Zhangye & 100.28 & 39.08 & 2008-2008 \\
\hline (35) Noto & 137.14 & 37.33 & $\overline{2001}-2013$ & & & & \\
\hline
\end{tabular}

* DRAGON2012: period of the DRAGON-NE Asia 2012 campaign (March-May 2012)

summer depending on snow surface and summer monsoon. The uncertainty related with the BAOD assumption will be discussed in Sect. 3.5.

\section{Single channel algorithm}

The basic concept of the single-channel algorithm suggested in Kim et al. (2014) lies in the inversion of the top of the atmosphere (TOA) reflectance to AOD by using the sensitivity of the TOA reflectance to AOD under the condition of fixed aerosol model, with known geometry and retrieved surface reflectance. The sensitivities of the reflectance to each variable are from a forward model, a radiative transfer model (RTM), assuming certain microphysical properties of the aerosol. The results are compiled into a LUT, where the assumed characteristics of the AOPs form the basis for the aerosol model. Generally, the LUT for a single-channel algorithm lists the calculated reflectance as a function of AOD, surface reflectance, measurement geometry, and the assumed aerosol model. In this study, a dynamic aerosol model was 


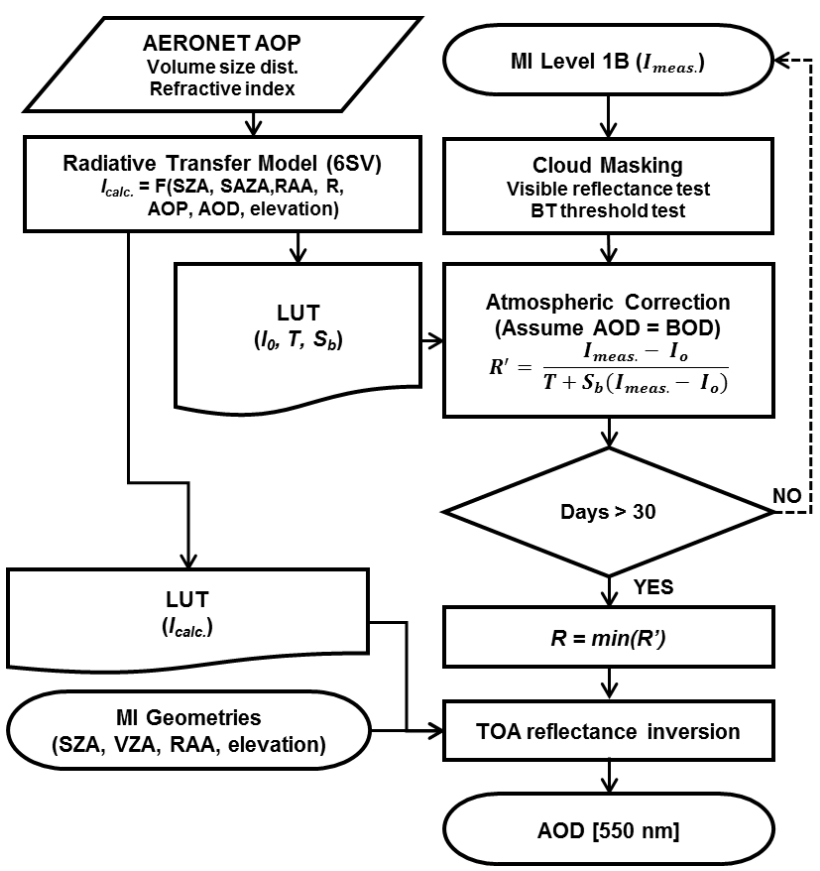

Figure 3. Flowchart of a single-channel algorithm for AOD retrieval, adapted from Kim et al. (2014). $I_{\text {meas }}$ and $I_{\text {calc }}$ represent measured and calculated TOA reflectance, respectively. $I_{\mathrm{O}}$ means atmospheric reflectance including the Rayleigh scattering and aerosol effect, $S_{b}$ is the hemispheric reflectance, and $T$ is the atmospheric transmittance for the geometry of the sun illumination and satellite viewing. $R^{\prime}$ shows semi-surface reflectance obtained by correcting the atmospheric effects from the $I_{\text {meas }}$ and the minimum value among the 30 -day $R^{\prime}$ is regarded as the surface reflectance $(R)$.

constructed using long-term AERONET inversion data to consider changes in refractive index, the mode radius and the width (standard deviation) in the volume size distribution with respect to the AOD. The volume size distribution consists of two modes, fine and coarse, and both vary in accordance with assumed AOD in the RTM simulation. In addition, the aerosol model was designed to include the seasonal variation in AOPs, with a different LUT selected depending on the season in which the measurement was taken. A flowchart of the AOD retrieval algorithm for MI measurements is shown in Fig. 3. To estimate surface reflectance, the minimum reflectance method was applied under the assumption that the increase in AOD makes a positive contribution to TOA reflectance over a dark surface. The minimum TOA reflectance obtained from the previous 30-day measurement was converted to surface reflectance, after correcting for scattering by atmospheric molecules and for BAOD.

\subsection{Cloud masking}

The AOD was retrieved only for cloud-free pixels which satisfy threshold tests of TOA reflectance and BT. The threshold of 0.35 for the TOA reflectance at the visible channel separated bright cloud pixels, and the threshold of $5 \mathrm{~K}$ for the BT difference between the maximum BT for the previous 30 days and the BT of the current pixel separated cold cloud pixels. The pixels which have a BT lower than $265 \mathrm{~K}$ were also masked out. Additionally, thresholds for BT differences between IR1 and IR2, and IR1 and IR4 were taken from Frey et al. (2008). The thresholds to distinguish cloud and aerosol pixels (IR1 - IR2 brightness temperature difference (BTD)), and to detect low-level clouds (IR1 - IR4 BTD) were adjusted as follows by trial and error. The positive BTD between IR1 and IR2, and the largely negative BTD $(<-6 \mathrm{~K})$ were found in cloud pixels. Thus, the cloud masking procedure includes the following tests:

visible reflectance $>0.35$

IR $1-$ IR2 $>0.5 \mathrm{~K} \&$ IR $1<268 \mathrm{~K}$

IR $1-$ IR2 $>0.5 \mathrm{~K} \&$ IR 1 max - IR $1>5 \mathrm{~K}$

IR $1-$ IR $2>1.5 \mathrm{~K} \&$ IR $1-$ IR $4<-6 \mathrm{~K}$ for ocean

IR $1-$ IR $2>0.5 \mathrm{~K} \& \mathrm{IR} 1-\mathrm{IR} 4<-10 \mathrm{~K}$ for ocean

IR $1-$ IR2 $>1.5 \mathrm{~K} \&$ IR $1-$ IR $4<-14 \mathrm{~K}$ for land.

\subsection{Surface reflectance and BAOD}

The BAOD represents a residual AOD value even in the clearest conditions, i.e., the minimum AOD for each location. According to analyses of global AERONET direct measurements, the minimum AOD over urban areas or near an aerosol source region is non-zero due to the steady emission of aerosol (Kim et al., 2016). An underestimation of BAOD results in an underestimation of retrieved AOD. In an environment of continuous development, population growth, and desertification, the BAOD is not negligible, particularly over East Asia. Accordingly, Kim et al. (2014) used the monthly BAOD obtained from AERONET direct measurements in Hong Kong for AOD retrieval in the region. Subsequently, the BAOD was estimated from the MODIS AOD product for 7 years from 2006 to 2012, and used here in order to take advantage of the fine spatial resolution of the satellite measurements. The BAOD ranged from 0.00 to 0.56 , with an average value of 0.03 (Fig. 4). Over the ocean, spatial variation of BAOD was not significant because the background aerosol is most likely sea salt with the median value of 0.022 . Over land, however, the spatial distribution of BAOD was related to surface type. While the median of BAOD over land was 0.017, the values near metropolitan areas such as Beijing, Seoul, Tokyo, and Hong Kong were generally higher than 0.1. Over the industrialized region located in the lower reaches of the Yangtze River and near Hong Kong, the values even reached over 0.30. Conversely, the region located far from the aerosol source showed low BAODs. Overall, the 


\section{Background aerosol optical depth from MYD04}

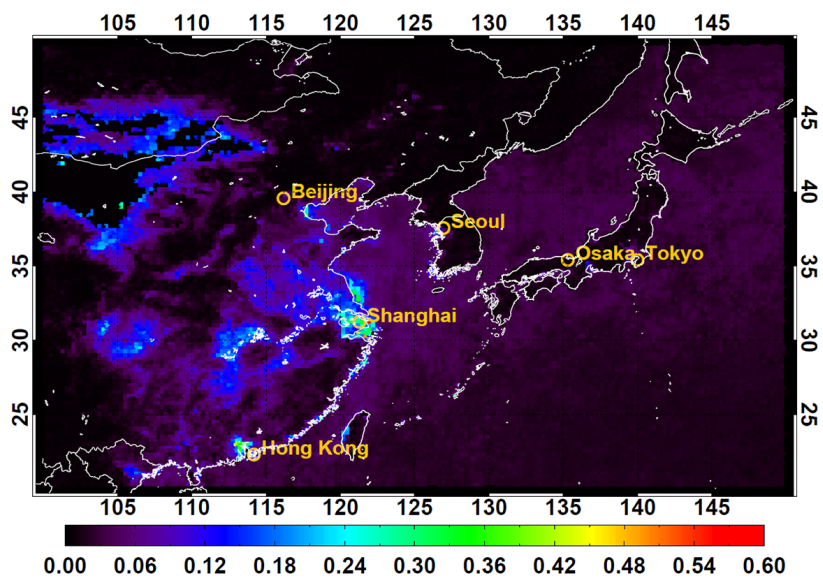

Figure 4. Absolute minimum $\mathrm{AOD}$ at $550 \mathrm{~nm}$ obtained from MODIS level 2.0 products (MYD04_Lv2.0) from 2006 to 2012 at $0.25^{\circ} \times 0.25^{\circ}$ resolution. Yellow circles indicate the location of well-known urban areas over northeast Asia.

BAOD map clearly reveals the most heavily polluted region as a hotspot.

The surface reflectance was estimated from the minimum TOA reflectance, after correcting for atmospheric and BAOD effects. For details of the atmospheric correction, see Kim et al. (2014).

\subsection{Integration of aerosol model}

The calculated TOA reflectance from RTM simulations is affected by the concentration, particle size/shape, and scattering properties of aerosol. Consequently, an increase in the SSA of the particle correlates positively with TOA reflectance for the same AOD. The use of a well-defined aerosol model to generate the LUT is therefore crucial to obtain accurate AOD values from the inversion method. Although spatial variation of the aerosol characteristics shown in Fig. 2 was not taken into account, a regionally integrated aerosol model over the area of interest suggests typical properties from these areas, since the geostationary MI steadily observes the same field of view from a fixed location. In this study, the aerosol models were obtained from a seasonal average of AERONET inversion data sets over East Asia. There are two groups of inversion data sets applied to examine the effect of the DRAGON-NE Asia campaign on the retrieval accuracy of aerosol. The first data sets were compiled from 18 AERONET sites from 1999 to 2010, with a total of 4898 data points as used by Kim et al. (2014). This group was named as the "original" data set, where the name and location of these sites are represented by italic type. The full list shown by normal characters in Table 1 summarizes the sites used to construct the new data set as described in Sect. 2.1.
The new group includes 40 additional AERONET sites and extends the measurement period by up to 2 years (20112012) including the campaign. The greater quantity of data, from the increased number of sites for the extended measurement periods, allows us to optimize the aerosol model for the region of interest.

To compare the effects of the temporal extension and spatially more dense measurements, the integrated AOPs for each case are presented in Table 2. In the table, AOPs considered to calculate LUT for the MAM (March, April, and May) season were listed for each AOD bin in order of SSA, refractive index, effective radius and standard deviation of volume size distribution, and the number of integrated data. To consider the change in AOP with respect to AOD suggested by Levy et al. (2007a), the AOPs were categorized into six AOD bins. The bins are categorized by $0.0-0.3,0.3-0.6,0.6-1.0$, $1.0-1.4,1.4-1.8$, and 1.8-3.0, and the median values of each AOD bin are shown in Table 2. Though AERONET inversion data provide four spectral SSAs at 440,675, 870, and $1020 \mathrm{~nm}$, the values at $675 \mathrm{~nm}$ were analyzed considering the spectral range of the MI visible channel. For the LUT calculation, however, wavelength dependence of the refractive index was obtained from the AERONET retrieval and applied. Based on the wavelength dependence, the AOD was retrieved at $550 \mathrm{~nm}$. The total average and standard deviation of the SSA for the original group (Table 2a) was 0.92 and 0.035 , respectively. The SSA ranged between 0.911 and 0.925 in order of AOD. Accordingly, the real part of the refractive index showed positive correlation with the AOD. The increase of AOD caused the increase of effective radius and standard deviation of fine-mode size distribution, too. With the quality criteria of the inversion products, the number of data points was significantly low for the low AOD bin. The number of data was also decreased with the increasing AOD. In Table $2 b$, the AOPs obtained from the temporally extended data sets from the same sites were listed. A slight increase of the effective radius for coarse-mode particles was found for the low AOD cases in accordance with the increase of the number of data. When the data set from the DRAGON-NE Asia campaign, and a few additional sites in China not included in the original study, were applied, all AOD bins showed an increase in SSA by more than 0.005, and the average value was $0.93 \pm 0.035$. The larger data set resulted in an increase in SSA by about $1 \%$, though the variation is lower than the standard deviation of SSA. The increase in SSA may also be due to a temporal change in SSA which was suggested in Lyapustin et al. (2011a). The previous study showed increases in SSA in eastern China from 2000 to 2010 by about 0.02 at $470 \mathrm{~nm}$. The imaginary part of the refractive index was generally decreased, and the decrease was more significant for low AOD condition than high AOD conditions. Meanwhile, the increasing effective radius of coarse particles was also found. Figure 5 shows the volume size distribution analyzed from the original (Fig. 5a) and the new data (Fig. 5b) group for each AOD bin. In general, 
Table 2. Integrated AOPs for each AOD bin $(550 \mathrm{~nm})$ from AERONET inversion data. Each of the AOD bins ranges between 0.0 and 0.3 , 0.3 and 0.6, 0.6 and 1.0, 1.0 and 1.4, 1.4 and 1.8, and 1.8 and 3.0, respectively, and the median value is shown in the table. The values in (a) (upper panel) were obtained from the original inversion data group, and those in the middle and lower panels (b and c) were estimated from temporally and temporal-spatially extended data sets, respectively. Fine and course modes are denoted by $-\mathrm{F}$ and $-\mathrm{C}$, respectively.

\begin{tabular}{|c|c|c|c|c|c|c|}
\hline \multirow[t]{2}{*}{ (a) Original aerosol model } & \multicolumn{6}{|c|}{ AOD } \\
\hline & 0.15 & 0.45 & 0.8 & 1.2 & 1.6 & $>2.6$ \\
\hline SSA at $675 \mathrm{~nm}$ & 0.911 & 0.921 & 0.928 & 0.932 & 0.939 & 0.945 \\
\hline Refractive index (real) at $675 \mathrm{~nm}$ (SD) & $1.47(0.06)$ & $1.47(0.05)$ & $1.47(0.05)$ & $1.49(0.05)$ & $1.53(0.05)$ & $1.52(0.06)$ \\
\hline \multirow[t]{2}{*}{ Refractive index (im.) at $675 \mathrm{~nm}$ (SD) } & 0.0085 & 0.0075 & 0.0077 & 0.0075 & 0.0060 & 0.0050 \\
\hline & $(0.0046)$ & $(0.0050)$ & $(0.0049)$ & $(0.0044)$ & $(0.0041)$ & $(0.0032)$ \\
\hline Effective radius- $\mathrm{F}(\mu \mathrm{m})$ & 0.14 & 0.15 & 0.18 & 0.19 & 0.18 & 0.20 \\
\hline Effective radius- $\mathrm{C}(\mu \mathrm{m})$ & 1.76 & 1.90 & 2.08 & 2.16 & 2.01 & 2.03 \\
\hline Standard deviation-F & 0.45 & 0.47 & 0.51 & 0.54 & 0.55 & 0.56 \\
\hline Standard deviation-C & 0.69 & 0.64 & 0.62 & 0.58 & 0.54 & 0.52 \\
\hline Number of data & 55 & 528 & 270 & 87 & 26 & 21 \\
\hline \multirow[t]{2}{*}{ (b) Updated aerosol model (temporally extended) } & \multicolumn{6}{|c|}{ AOD } \\
\hline & 0.15 & 0.45 & 0.8 & 1.2 & 1.6 & $>2.6$ \\
\hline SSA at $675 \mathrm{~nm}$ & 0.910 & 0.923 & 0.932 & 0.935 & 0.940 & 0.949 \\
\hline Refractive index (real) at $675 \mathrm{~nm}(\mathrm{SD})$ & $1.48(0.06)$ & $1.47(0.05)$ & $1.48(0.05)$ & $1.49(0.05)$ & $1.52(0.05)$ & $1.51(0.05)$ \\
\hline \multirow[t]{2}{*}{ Refractive index (im.) at $675 \mathrm{~nm}$ (SD) } & 0.0083 & 0.0072 & 0.0071 & 0.0070 & 0.0059 & 0.0048 \\
\hline & $(0.0049)$ & $(0.0086)$ & $(0.0047)$ & $(0.0044)$ & $(0.0036)$ & $(0.0031)$ \\
\hline Effective radius-F $(\mu \mathrm{m})$ & 0.14 & 0.15 & 0.17 & 0.18 & 0.18 & 0.20 \\
\hline Effective radius- $\mathrm{C}(\mu \mathrm{m})$ & 1.84 & 1.94 & 2.09 & 2.16 & 2.02 & 2.01 \\
\hline Standard deviation-F & 0.45 & 0.47 & 0.51 & 0.54 & 0.53 & 0.56 \\
\hline Standard deviation-C & 0.69 & 0.64 & 0.61 & 0.58 & 0.55 & 0.53 \\
\hline Number of data & 75 & 677 & 370 & 112 & 37 & 31 \\
\hline \multirow[t]{2}{*}{ (c) Updated aerosol model (temporal-spatially extended) } & \multicolumn{6}{|c|}{ AOD } \\
\hline & 0.15 & 0.45 & 0.8 & 1.2 & 1.6 & $>2.6$ \\
\hline SSA at $675 \mathrm{~nm}$ & 0.916 & 0.927 & 0.935 & 0.940 & 0.944 & 0.951 \\
\hline Refractive index (real) at $675 \mathrm{~nm}$ (SD) & $1.48(0.06)$ & $1.48(0.05)$ & $1.48(0.05)$ & $1.50(0.05)$ & $1.51(0.05)$ & $1.51(0.05)$ \\
\hline \multirow[t]{2}{*}{ Refractive index (im.) at $675 \mathrm{~nm}$ (SD) } & 0.0073 & 0.0065 & 0.0061 & 0.0060 & 0.0054 & 0.0046 \\
\hline & $(0.0043)$ & $(0.0072)$ & $(0.0041)$ & $(0.0040)$ & $(0.0039)$ & $(0.0037)$ \\
\hline Effective radius- $\mathrm{F}(\mu \mathrm{m})$ & 0.14 & 0.15 & 0.16 & 0.17 & 0.17 & 0.20 \\
\hline Effective radius- $\mathrm{C}(\mu \mathrm{m})$ & 1.87 & 1.95 & 2.07 & 2.11 & 2.05 & 1.98 \\
\hline Standard deviation-F & 0.46 & 0.48 & 0.51 & 0.55 & 0.57 & 0.56 \\
\hline Standard deviation-C & 0.69 & 0.65 & 0.61 & 0.58 & 0.55 & 0.54 \\
\hline Number of data & 219 & 1431 & 767 & 235 & 74 & 51 \\
\hline
\end{tabular}

the coarse-mode particles of a bimodal log-normal size distribution tend to dominate due to sporadic dust events (e.g., Lee et al., 2010). With the increase in AOD, the mode radius of fine particles is increased, while that of coarse particles is decreased (Levy et al., 2007a). The effective radius and standard deviation values for fine and coarse mode are listed in Table $2 \mathrm{a}$ and $\mathrm{c}$.

Using aerosol models derived from both the original and new data sets, LUTs were calculated by using the 6SV (Second Simulation of a Satellite Signal in the Solar SpectrumVector) RTM (Vermote et al., 1997; Kotchenova et al., 2006; Kotchenova and Vermote, 2007). In addition to measurement geometry (i.e., solar zenith angle, viewing zenith angle, and relative azimuth angle), the surface reflectance, aerosol model, and AOD were provided as input variables to cal- culate the LUTs. Surface elevation was also included to increase the accuracy of Rayleigh scattering correction.

As mentioned above, the AOD is retrieved by comparing measured and calculated TOA reflectance for a given set of measurement conditions. The values in the LUTs were linearly interpolated with the values in the neighboring bins because the calculation of TOA reflectance is performed as a function of several input variables. To test the effects of the changes in aerosol models, the AODs were respectively derived by using the original and the new LUTs.

\subsection{Sensitivity to assumed aerosol optical properties}

To estimate the accuracy of retrievals from the inversion of the single-channel algorithm, and to understand its sensitivity 

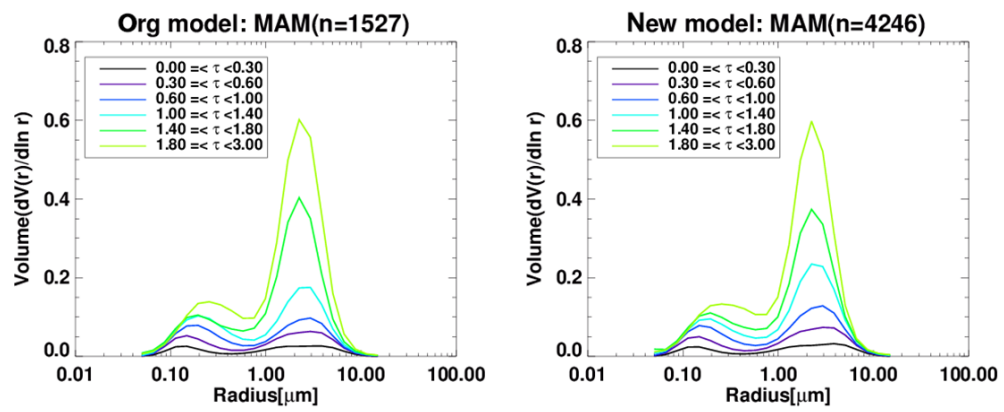

Figure 5. Volume size distribution for each AOD bin, as obtained from the original and new AERONET inversion data listed in Table 1. The effective radius and standard deviation of the fine- and coarse-mode particles are described in Table 2. The size distributions are averaged for each AOD interval, and the color of the curve indicates the mean AOD value.

to uncertainty in the assumed SSA, a reference test was performed. In this test, the TOA reflectance was analyzed within a $\pm 4 \%$ variation in SSA relative to the reference condition, from simulations using the RTM for four different reference conditions of both AOD and SSA with assumed geometries. The $4 \%$ variation covers the standard deviation of 0.035 for the integrated SSA of 0.92 mentioned in Sect. 3.3. In the simulation, the surface reflectance was assumed to be 0.05 and 0.10 , and the scattering angle was varied from 135.7 to $173.2^{\circ}$ with respect to the geostationary measurement conditions. The surface elevation was at sea level, and cloud-free conditions were assumed. The retrieved AOD from the simulated reflectance was then compared with the assumed reference AOD value. Because the AOD was retrieved from the simulated TOA reflectance by assuming the reference SSA, the $\pm 4 \%$ variation in SSA causes an error in AOD. The results for the comparison between the reference value and retrieved AODs for each simulated reflectance are shown in Fig. 6. The case with zero SSA error indicates that the assumed SSA for the retrieval was the same as the reference SSA. In other cases, the positive error in SSA indicates that the SSA used to calculate the LUT was overestimated when compared with the reference value. The errors in AOD and SSA were calculated as follows:

\section{$\mathrm{AOD}$ error $[\%]=$}

[(retrieved AOD - reference AOD)/referenceAOD] 100 SSA error [\%] $=$

[(assumed SSA - reference SSA)/reference SSA] 100.

Strong negative correlation was found between the errors in SSA and AOD. The error in SSA was negatively correlated with the error in AOD, and thus the overestimation of SSA leads to an underestimation of AOD. In terms of the absolute value of AOD error, the effects of the positive and negative errors in SSA are symmetric in general, though the effect of the negative error in SSA is slightly greater. The effect of assumed errors in SSA is more significant in scenarios with higher AOD. The SSA error of $\pm 3 \%$ results in an AOD error of $-18.70 \%(-0.03$, an absolute difference) and $+20.34 \%$ $(+0.03)$, respectively, when the reference AOD is 0.15 and the surface reflectance is 0.05 . The range of error is increased when the reference AOD is higher, with retrieval errors of $-20.03 \%(-0.24)$ and $+23.31 \%(+0.28)$ caused by a $\pm 3 \%$ SSA error when the reference AOD is 1.20.

The error in AOD also increases with the increase of assumed surface reflectance relative to true reflectance. When the surface reflectance is increased from 0.05 to 0.10 , the errors in the reference AOD of 0.15 ranged between $-35 \%$ $(-0.05)$ and $36 \%(+0.05)$. The increase of effect of the SSA assumption was related with the one-to-one correlation between the critical reflectance and SSA reflectance (Castanho et al., 2008; Fraser and Kaufman, 1985). Whereas the increase in aerosol contributes to the increase of TOA reflectance over a dark surface, the increase in AOD reduces the TOA reflectance by shielding the upwelling reflectance from a bright surface. There exists, therefore, a surface reflectance at which the positive and negative contributions of aerosol to the TOA reflectance are canceled out; then the surface reflectance is known as the critical reflectance. In consideration of the positive relationship between the critical reflectance and SSA, the sensitivity to the SSA assumption of the AOD retrieval can be increased near the critical reflectance.

\subsection{Uncertainty of AOD retrieval}

Various uncertainties result in an error in retrieved AOD as the algorithm is based on a single channel, where most dominant uncertainties come from estimating the surface reflectance and assumed aerosol model. To investigate the retrieval error, several sensitivity tests were conducted. The effects of linear inversion error, assumptions of BAOD, the aerosol model, and surface elevation were estimated in a quantitative manner in addition to the aerosol model error shown in Fig. 6.

The LUT approach has been widely used to obtain aerosol information from satellite measurements by reducing the operation time. In the LUT approach, the calculated value is 

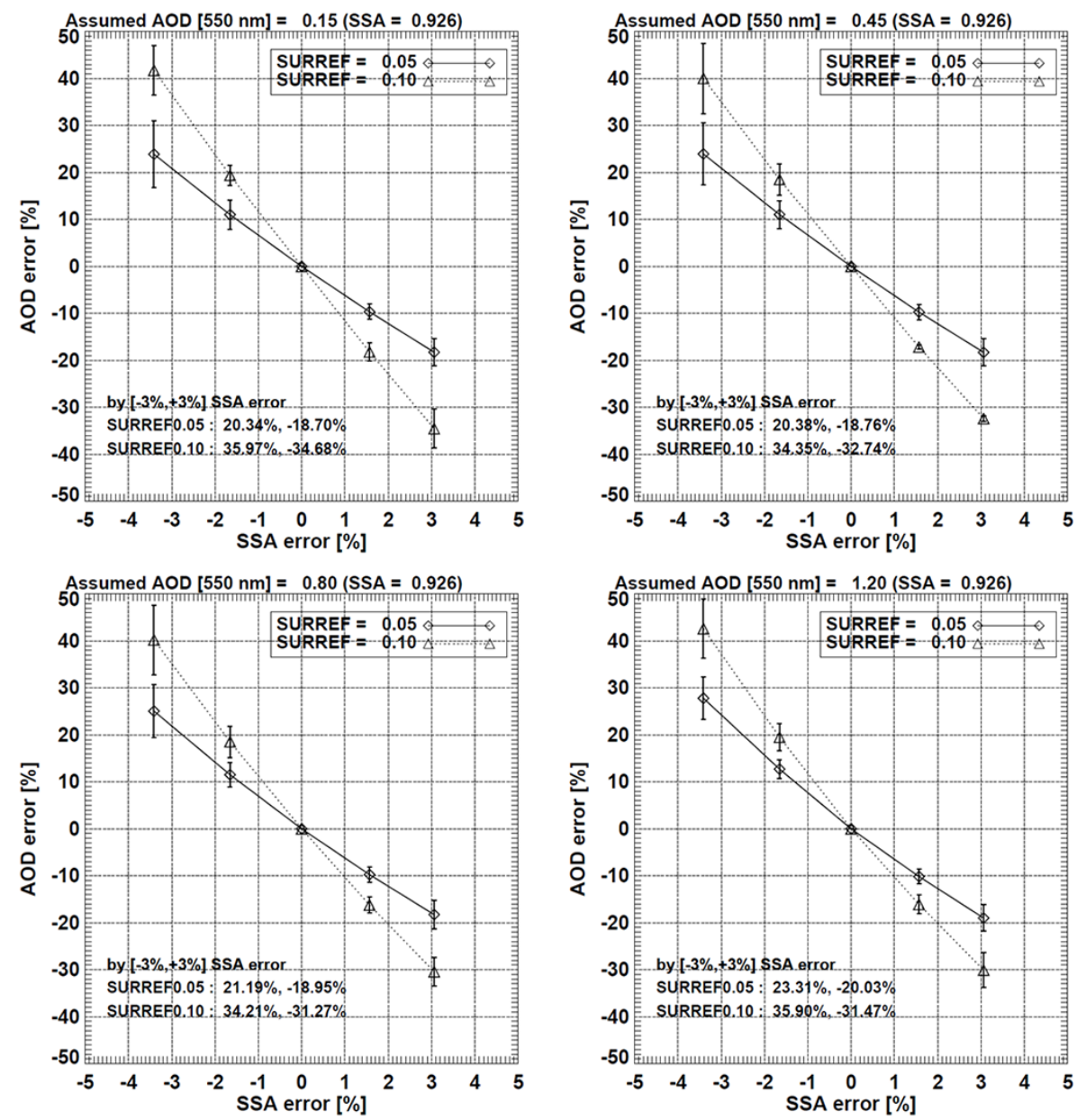

Figure 6. Dependence of the AOD retrieval error on error in assumed SSA for four different AOD cases. The SSA error represents the percentage difference between SSAs used in the simulation and the retrieval, and the AOD error indicates the difference between the retrieved AOD and a reference value. Surface reflectance is assumed to be 0.05 , and scattering angles ranging from $135.73^{\circ}$ to $173.23^{\circ}$ are applied. The error bars indicate the standard deviation of AOD error obtained from the geometric variation, and the numbers in parentheses are the SSA error without the inversion error.

interpolated linearly from the neighboring bins for geometry, AOD, surface reflectance, and elevation. Thus, the number of entries for LUT calculation must be selected carefully to save operation time and maintain retrieval accuracy at the same time. LUT applied in this study presents TOA reflectance calculated as a function of geometrical angles of sun and satellite with $10^{\circ}$ interval, and surface reflectance with 0.1 intervals. As long as the LUT approach is applied to the retrieval algorithm, the linear interpolation of TOA reflectance between each bin leads to the inversion error. Figure $7 \mathrm{a}$ and $\mathrm{b}$ show the percentage difference between retrieved and reference AODs in terms of scattering angle, surface reflectance, and AOD condition. Two different AODs of 0.15 and 1.20 were applied to calculate the reference reflectance with two surface reflectances of 0.05 and 0.10 , and solar zenith angles ranging from 0 to $57^{\circ}$ by intervals of $3^{\circ}$. The satellite zenith and azimuth angle were assumed to be 10 and $40^{\circ}$, respectively. In Fig. 7a and b, the percentage errors increase by increasing difference between the reference condition and LUT bin in terms of both scattering angle and surface reflectance. The inversion error varied from 0 to $8 \%$, which mainly increased with the increase of scattering angle, and decreased with the increase of AOD. In the figure, the solid lines represent the inversion error which has arisen solely by the angle interpolation in intervals of 0.1 for the surface reflectance in LUT. The dashed lines representing the inversion error for the surface reflectance of 0.05 show that the assumption about linearity between bins of surface reflectance increased the error negatively.

In the estimation of surface reflectance, the BAOD correction was applied to consider continuous emission of air pollutant over East Asia. However, the BAOD estimated from MODIS products contains retrieval uncertainty of the dark target algorithm. As mentioned above, the expected error 

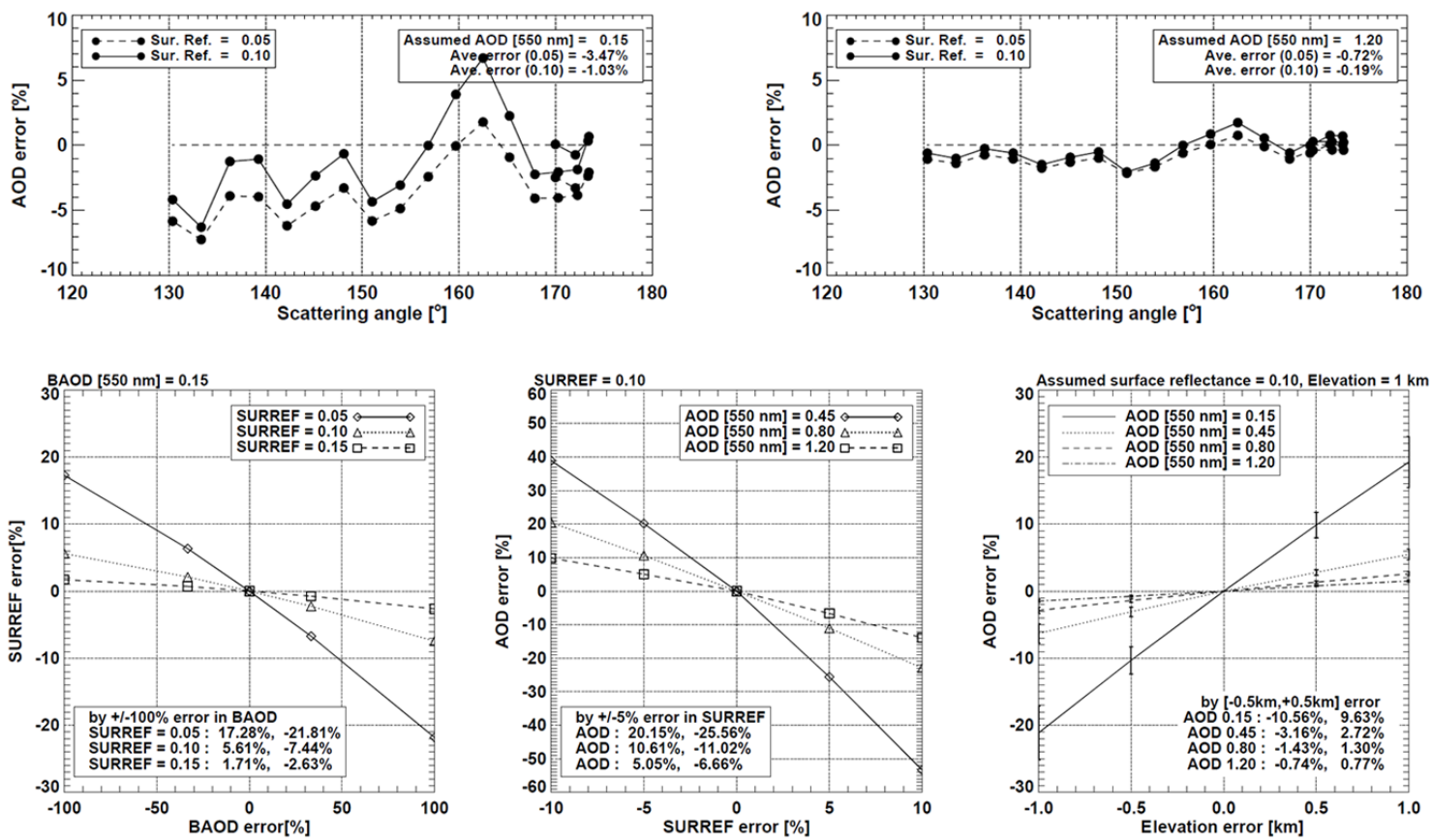

Figure 7. Uncertainties in retrieval of AOD and surface reflectance; (a, b) AOD error depending on scattering angle for two cases of AOD $(0.15,1.20)$ and two cases of surface reflectance $(0.05,0.10)$; (c) error in surface reflectance according to BAOD assumption error for three conditions of BAOD $(0.05,0.10$, and 0.15$)$; and (d) sensitivity of AOD error to error in surface reflectance and elevation for each assumed condition of AOD.

range of MODIS AOD is $\pm(0.05+15 \%)$. The BAOD is very low in general, and thus the expected error range can be over $\pm 100 \%$ when the BAOD is lower than 0.05 . According to a sensitivity test, the $\pm 100 \%$ error in the BAOD of 0.05 led to a $7 \%$ error in surface reflectance of 0.05 and an $11 \%$ error in AOD of 0.45. The effects of BAOD error in surface reflectance and AOD are shown in Fig. 7c and d, respectively, under the conditions of BAOD of 0.15 , three surface reflectances of 0.05, 0.10, and 0.15, and three AODs of 0.45, 0.80 , and 1.20. In general, the underestimation of the BAOD leads to the overestimation of the surface reflectance. The $-100 \%$ error in the BAOD assumption caused $5.6 \%$ overestimation of surface reflectance when the surface reflectance was 0.1 . Meanwhile, the $5 \%$ error in surface reflectance led to $25.56 \%$ underestimation of the AOD when the reference AOD and surface reflectance were 0.45 and 0.10 , respectively. The uncertainty decreased with the increase of surface reflectance, and the sensitivity to the error in surface reflectance was more significant for the low AOD condition than the high AOD. In this test, the inversion error was avoided by using reference reflectance calculated under the condition of LUT bins.

Lastly, the effect of assumption in surface elevation was analyzed, as shown in Fig. 7e. The assumption of surface elevation is linked with the Rayleigh scattering correction. The underestimation of surface elevation leads to the overestimation of atmospheric pressure, and thus the over-correction of the Rayleigh scattering, which eventually results in the overestimation of surface reflectance, and thus the underestimation of the AOD. The sensitivity was tested for an elevation of $1 \mathrm{~km}$, two AODs of 0.15 and 0.80 , and a surface reflectance of 0.10 . The $\pm 0.5 \mathrm{~km}$ errors in surface elevation resulted in $+9.63 \%$ and $-10.56 \%$ errors in AOD when the reference condition was assumed to be an AOD of 0.15. The increasing AOD significantly reduced sensitivity to the uncertainty, and a $\pm 0.5 \mathrm{~km}$ error led to +1.30 and $-1.43 \%$ when the AOD was 0.80 . The dependence on surface reflectance and elevation was not significant.

From the uncertainty tests, the largest uncertainty was found in the aerosol model assumption by about $30 \%$ although the effect of each uncertainty was changed by conditions of AOD, surface reflectance, and sun-satellite geometry.

\section{Results and validation}

\subsection{Comparison with MODIS AOD}

The greatest advantage of geostationary measurements is the availability of more cloud-free observations by continuous measurements at high temporal resolution. Besides, the AOD derived from geostationary satellite measurements can minimize the uncertainty caused by the different and limited sampling of polar-orbiting satellites in the trend estimation (Yoon 


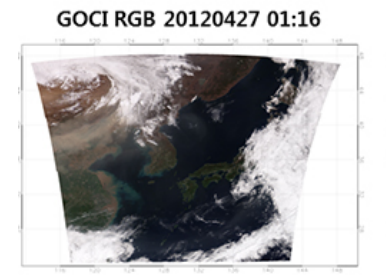

MI AOD 20120427 01:15

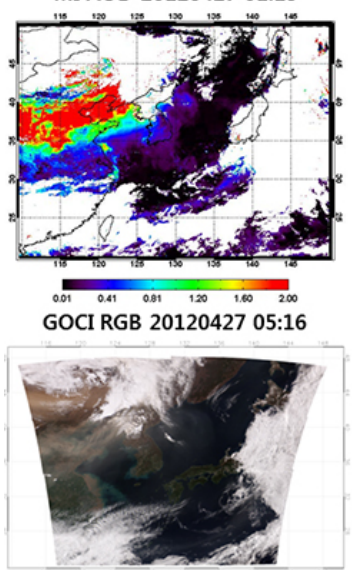

MI AOD 20120427 05:00

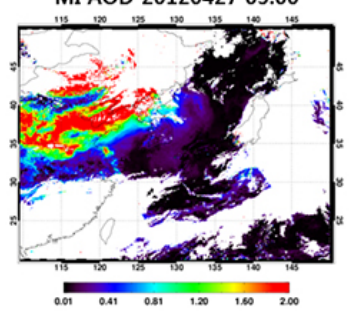

GOCI RGB 20120427 02:16

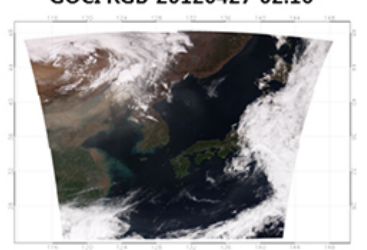

MI AOD 20120427 02:00

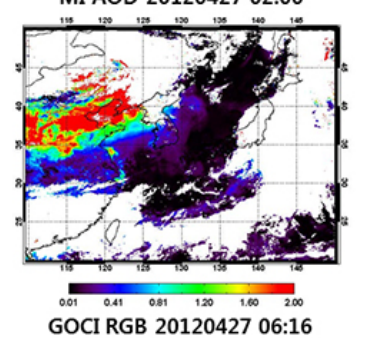

GOCI RGB 20120427 06:16

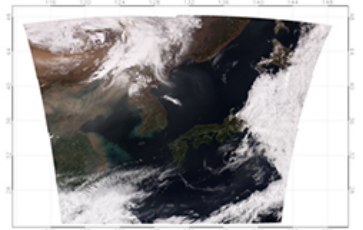

MI AOD 20120427 06:15

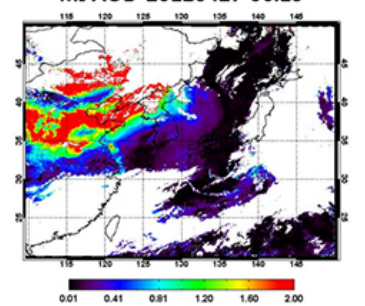

GOCI RGB 20120427 03:16

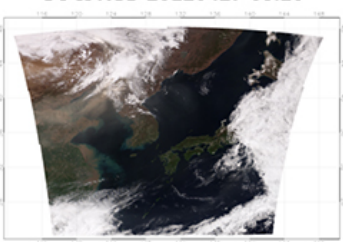

MI AOD 20120427 03:15

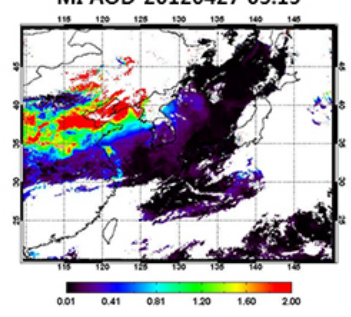

MOD AOD 20120427 00 - 05 UTC
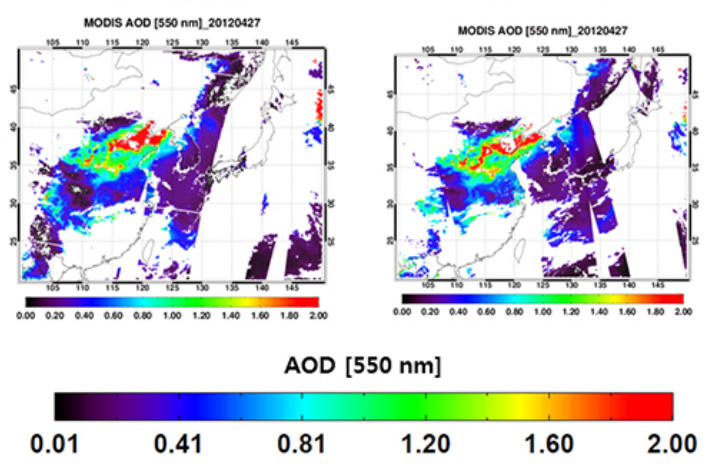

Figure 8. Red, green, and blue images obtained from GOCI measurements and examples of retrieved AOD from MI measurements on 27 April 2012. Two panels on the bottom right-hand side show the MODIS AOD product obtained from TERRA (MOD04) and AQUA (MYD04) measurements. The AOD ranges between 0 and 2 in these panels.

et al., 2014). Figure 8 shows examples of retrieved AOD from the geostationary measurements from MI, using the singlechannel algorithm. The red, green, and blue images, obtained from GOCI onboard the same platform measured at 01:16, 02:16, 03:16, 04:16, 05:16, and 06:16 UTC on 27 April 2012, show dust flow from the Shandong peninsula to the northern Korean peninsula. Similarly, the images of retrieved AOD show values greater than 1.0 in the dust plume, in contrast to the values lower than 0.4 over other regions. Compared with the MODIS AOD, the retrieved AODs over dusty regions are generally higher, though the distribution of MI AOD is spatially well matched over non-dusty regions. The spatially averaged value of the MI AOD in dusty regions $\left[110-125^{\circ} \mathrm{E}\right.$, $\left.35-40^{\circ} \mathrm{N}\right]$ decreased steadily from 2.67 at 00:00 UTC to 1.69 at 07:00 UTC, and the minimum value of 1.43 was found at 03:30 UTC. Meanwhile, the spatial mean values of AOD obtained from the MODIS TERRA and AQUA measurements were 1.11 at 03:55 UTC and 1.18 at 05:15 UTC respectively. In Fig. 8, the AOD images of TERRA and AQUA represent the measurements between 00:00 and 05:00 UTC, and between 02:00 and 06:00 UTC, respectively.

The results from MI also show the transport and concentration of aerosol in $30 \mathrm{~min}$ intervals, while the MODIS product can provide only two images per day. The map of MI AOD in hourly intervals shows that the high concentration of aerosol was mostly observed over northern China and the Yellow Sea before 03:00 UTC, with the dust plume extending to the East Sea across the northern Korean peninsula. We can deduce from the change in the dust plume that the wind field changed straight flow from southwest to northeast in the morning to a wave pattern, following a low pressure system located in Manchuria. Neither the dark target algorithm of MODIS nor the single-channel algorithm of MI could retrieve AOD over regions of brighter surfaces, due to the low sensitivity of the aerosol compared with the surface. However, unlike the MI retrieval, part of the dust scene over the ocean was missed in the MODIS retrieval due to sun glint masking. 

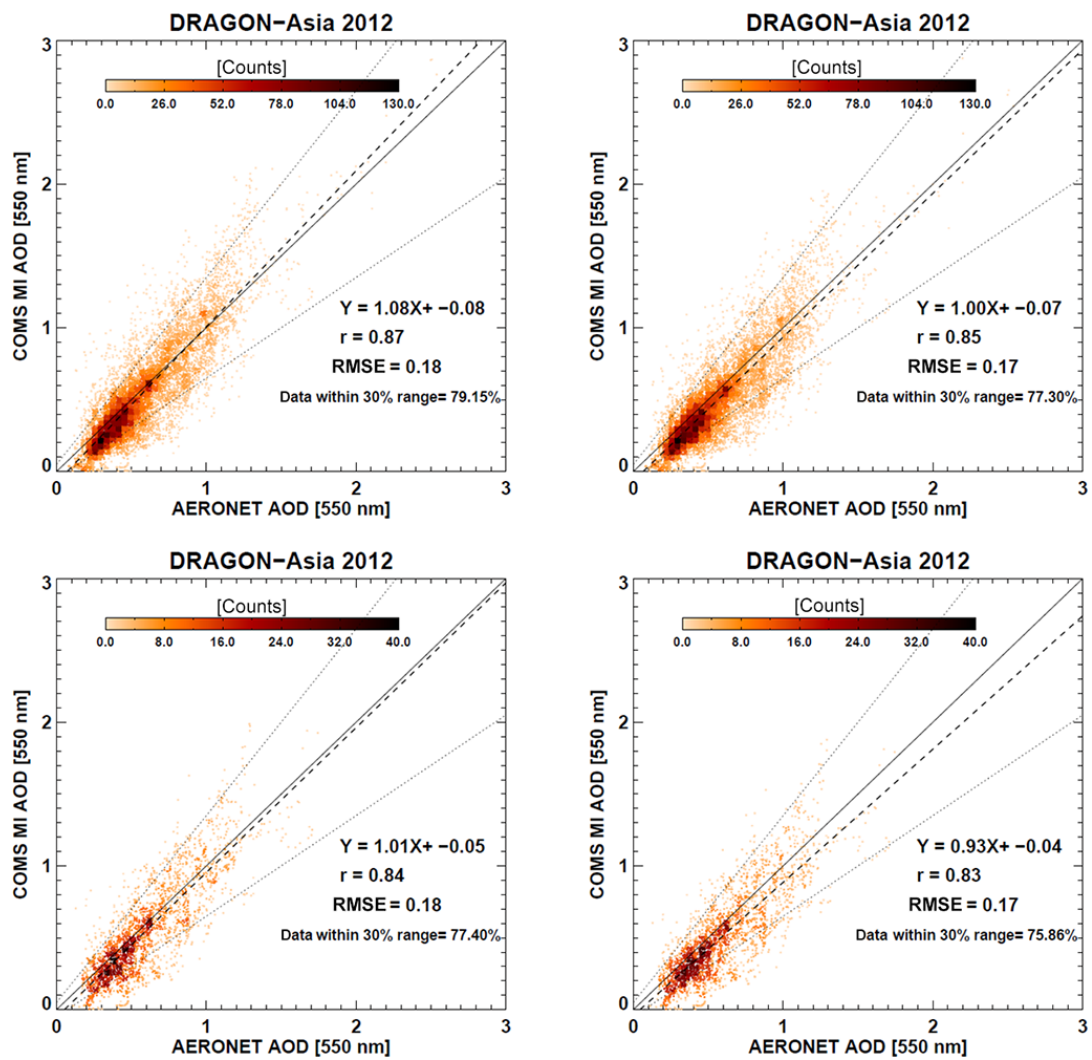

Figure 9. Evaluation of the AOD retrieved from MI measurements during the DRAGON-NE Asia campaign. The $x$ axis and $y$ axis indicate the values of AOD at $550 \mathrm{~nm}$ obtained from AERONET and MI measurements, respectively, and the color of the symbols shows the data counts for each AOD bin. The $y$ axis on the left $(\mathbf{a}, \mathbf{c})$ and right side $(\mathbf{b}, \mathbf{d})$ represents the AOD retrieved using the original and new LUT, respectively. The plots at the top $(\mathbf{a}, \mathbf{b})$ contain the data measured from all campaign sites, whereas those at the bottom (c, d) contain only the values from the sites excluded from the AOP analysis. The linear regression line with a Pearson coefficient $(r)$ and root-mean-square error (RMSE) were included for each plot.

\subsection{Comparison with AERONET: DRAGON-NE Asia}

For quantitative validation, the retrieved AODs were compared with the measured values from the 39 AERONET sun photometer sites in Korea and Japan. To investigate the effect of the new aerosol model as an input parameter to calculate the LUTs, the results of the original and new AOD retrievals were compared, and the comparisons are shown in Fig. 9. The measured AODs from all of the numbered DRAGONNE Asia sites listed in Table 1 were used in the comparison shown in the top panel. In the lower panel, part of the AERONET AOD used as a validation group to test the consistency of the algorithm and to validate the retrieval accuracy is shown. The data from the validation group were not included in the AOP analysis due to a lack of inversion data sets. The comparison results are shown in the bottom panel of Fig. 9. The left and right panels show evaluations of the original and new AOD, respectively.
Using the original aerosol model, the retrieved AODs agree very well with the linear regression as follows:

$\tau_{\text {MI }[\text { original LUT }]}=1.08 \tau_{\text {DRAGON-Asia }}-0.08$,

$\mathrm{RMSE}=0.18, r=0.87$.

Although the Pearson coefficient of 0.87 indicates a significant correlation, the regression slope indicates that the retrieved AOD is overestimated by $8 \%$ compared with the AERONET value. Comparison with the validation group, however, shows a tendency to systematic underestimation, with a slope of 1.01 and $y$-offset of -0.05 .

By applying the new aerosol model, the regression slope was improved to 1.00 , although other measures remained similar:

$\tau_{\text {MI[new LUT }]}=1.00 \tau_{\text {DRAGON-Asia }}-0.07$,

$\mathrm{RMSE}=0.17, r=0.85$.

In Sect. 3.4, the analysis of the retrieval sensitivity to the SSA assumption showed that the underestimation of the SSA in the aerosol model results in the overestimation of AOD. 

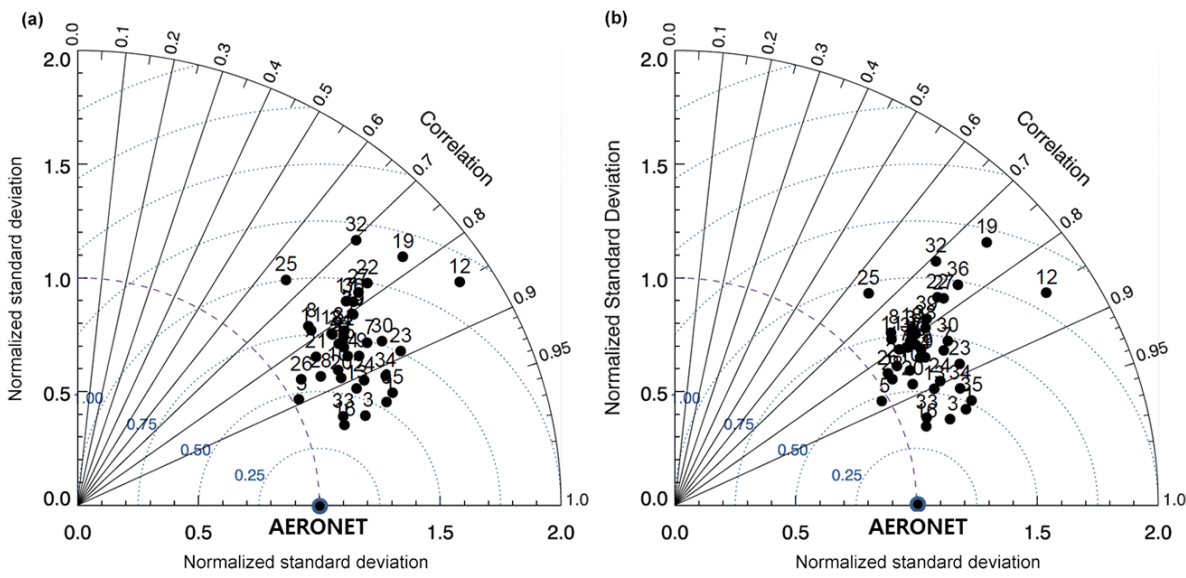

Figure 10. Taylor diagrams comparing the retrieved AODs and the values obtained from AERONET sun photometer measurements during the DRAGON-2012 campaign. (a) Comparison of results from the original AOD, (b) comparison of results from the new AOD. The numbers above each symbol indicate the number of the DRAGON-NE Asia sites, as listed in Table 1.

Thus, the overestimation of the original AOD suggests that the radiative absorptivity of the aerosol during MAM was slightly underestimated prior to the campaign. According to Fig. 6, a $1 \%$ underestimation of SSA can result in an overestimation of AOD by up to $7 \%$. The uncertainty can vary with measurement geometry, AOD, or surface reflectance. Therefore, to a large degree, the $8 \%$ decrease in AOD can be explained by a $1.1 \%$ increase in SSA in the new aerosol model during MAM. The large RMSE and the underestimation for the validation group, however, are attributed to the spatial and temporal variation in AOPs, which cannot be standardized by the single aerosol model. Moreover, the change of aerosol model results in a decrease of percentage of the comparison data within $30 \%$ difference range from 79.15 to $77.30 \%$. In terms of the comparison of the validation group, the regression slope decreased from 1.01 to 0.93 , though the comparison still shows strong correlation between the retrieved and measured AOD. As long as a single aerosol model is applied, the spatial and temporal variations of aerosol properties are the largest uncertainty of the AOD retrieval algorithm. When the difference between assumed and actual SSA becomes higher than $3 \%$, the retrieval error exceed $30 \%$. The degradation of the comparison statistics shows the limitation of the single-channel algorithm. The uncertainties in estimation of surface reflectance and assumption of linearity between LUT bins have effects on the accuracy of low AOD as described in Sect. 3.5. The sensitivity tests showed that the effects of each retrieval uncertainty depend on the condition of AOD. For the condition of low AOD, the effect of the aerosol model assumption on the retrieval uncertainty in AOD is significantly lower than the effects of surface reflectance estimation. However, an insufficient number of inversion data for an AOD bin between 0.0 and 0.3 , where the AOD is lower than the criteria of quality assurance of 0.4 $(440 \mathrm{~nm})$, increases the uncertainty in the assumption of the aerosol model for the condition of low AOD. Consequently, it was found that the validation statistics for low AOD $(<0.4$ at $550 \mathrm{~nm}$ ) were significantly lower than that for high AOD. While the correlation coefficient and regression slope of the low AOD comparison were 0.49 and 0.35 , those for the high AOD condition were 0.78 and 0.86 . The ratio of the low AOD to the total comparison data set was $41.72 \%$. To show the retrieval accuracy for each campaign site, the Taylor diagram (Taylor, 2001) is shown in Fig. 10. This diagram summarizes how closely a set of retrievals matches observations in terms of $r$, RMSE, and standard deviation. The polar angle of the point from the $x$ axis indicates the correlation coefficient, and the radial distance represents the normalized standard deviation, which in this case describes the ratio of the standard deviation of the retrieved MI AOD to that of the AERONET (Yoon et al., 2014) values. The distance between the symbol and the dashed arc, which represents the standard deviation of the AERONET value, shows the similarity of the amplitude of their variations; a radial distance of $>1$ indicates that the standard deviation of the MI AOD is greater than that of AERONET. On the other hand, the RMSE between the MI and AERONET AODs is proportional to the distance to the point on the $x$ axis identified as "AERONET", marked with a dotted arc. Consequently, the decrease in distance between the "AERONET" point and the position of the symbol indicates an increase in similarity between the retrieved and measured AODs. The normalized standard deviations of retrieved AOD generally range from 1 to 1.5 , except for the Kohriyama (site number 12) and Matsue (site number 19) in Japan. In spite of the high correlation coefficients of 0.85 and 0.78 at the sites, the high regression slopes of 1.58 and 1.35 suggest that the radiative absorptivity was underestimated in this region, and thus the AOD was significantly overestimated in the case of high-AOD conditions. The large negative $y$-intercepts of -0.12 and -0.25 could be caused by 
the underestimation of AOD following an overestimation of BAOD in the case of low-AOD conditions.

The comparison statistics of the original and new AOD, plotted in the Taylor diagram, are also listed in Tables 3 and 4 , respectively. The correlation coefficients obtained from the 39 DRAGON sites range from 0.66 to 0.95 and the average was 0.84 when the original aerosol model was applied. The maximum value was found at Anmyeon (site number 3) and Kunsan_NU (National University) in Korea, and the minimum value of 0.66 was found at Nishi-Harima (site number 25) in Japan. The Anmyeon site was located in a rural area near the ocean to monitor background conditions of the atmosphere (e.g., Kim et al., 2007), and thus the dark surface contributes to a reduction in the uncertainty in AOD retrieval. The Kunsan-NU site, as with the Anmyeon site, was surrounded by mountains, reservoirs, and an area that is rural. Meanwhile, the Nishi-Harima site was located on the top of Mount Onade (435.9 m altitude, Nishi-Harima Astronomical Observatory) among trees, and thus the uncertainty caused during surface correction can also be reduced. However, the comparison statistics showed systematic underestimation of the AODs by a regression slope of 0.86 and a $y$-intercept of -0.06 . To compare the difference between the AOD correlations for each sites, temporal variation of the AODs obtained from MI and AERONET measurements were represented in Fig. 11. In Fig. 11, the AOD variations for the four aforementioned sites are shown in order of the (a) Anmyeon, (b) Kunsan_NU, (c) Kohriyama, and (d) Nishi-Harima sites. The red boxes and black circles, which indicate the MI AOD and the AERONET values, were well matched at (a) Anmyeon and (b) Kunsan-NU with good correlation statistics. The vertical distribution of symbols for each day represents diurnal variation of AOD, and the variations were also highly correlated regardless of time. The temporal variations showed an increase in AOD during the period from 1 to 15 May at both sites. In two other sites in Japan, Kohriyama and NishiHarima, no temporal pattern can be found because of the low number of comparison data, though the variation of MI AOD was closely related with the AERONET value. A notable feature in the comparison was the low number of data. Table 3 showed that most Japanese sites (except Fukue) have a lower number of comparison data than the Korean sites, and the low number trend was related with the frequency of the direct measurements by the sun photometer in Japanese sites. While the total number of direct AOD products in the level 2.0 data set ranged between 99 and 3630 in Japan, the number ranged from 1296 to 5191 in Korea. The difference in data counts indicates that there were frequent rain and cloud events over Japan, resulting in uncertainty in the AOD retrieval in Japan, including the Koriyama and Nishi-Harima sites. However, a reason for the significant underestimation trend of the MI AOD at Nishi-Harima is not clear yet.

Excluding the Fukue_2 site, which has a low number of comparison data of only 4, the regression slopes at 32 AERONET sites were higher than 1.0, and the values at 9
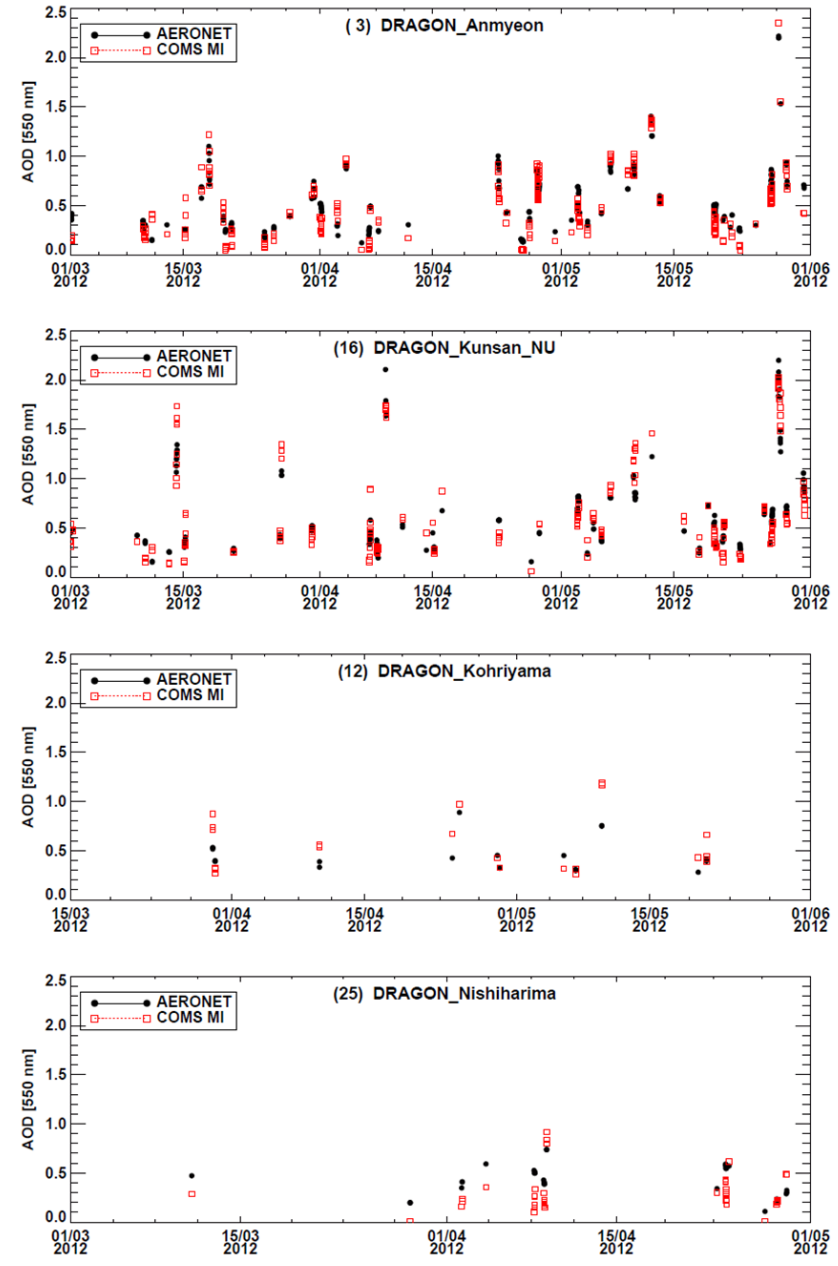

Figure 11. Temporal variations of AODs during the DRAGON-NE Asia campaign. The red boxes and black circles represent the values retrieved from MI and AERONET measurements, respectively, and each panel shows the time series for different AERONET sites: (a) Anmyeon, (b) Kunsan_NU, (c) Kohriyama, (d) Nishi-Harima.

sites exceeded 1.2. As well as the Kohriyama and the Matsue sites, the comparison results for all but three sites (2, 30, and 32) show negative $y$-intercepts between -0.003 and -0.25 . As with the improved correlation seen in the scatter plot, the Taylor diagram and regression statistics listed in Table 4 also show improvements in retrieval accuracy at each site. The distances between the data point and the AERONET value at each site were generally reduced, especially at Tsukuba (site number 32). At this site, the systematic overestimation was significantly reduced by applying the new aerosol model, also leading to an improved correlation coefficient. The regression slope over all sites decreased by about 0.08 , while the $y$-intercept changed within a range from -0.03 to 0.06 , in accordance with the increased SSA in the new aerosol model. Whereas most of the comparisons were improved by the decrease in the slope, some sites $(11,21,25,26,28$, and 36) show a better result using the original aerosol model in terms 
Table 3. Summary statistics of the comparison between the MI AOD (550 nm) retrieved with the original LUT and AERONET AOD $(550 \mathrm{~nm})$. The site numbers correspond to the numbers listed in Table 1 and Fig. 9a. The sites mentioned in Sect. 4.2 are represented by bold font.

\begin{tabular}{|c|c|c|c|c|c|c|c|c|}
\hline $\begin{array}{l}\text { Site } \\
\text { no. }\end{array}$ & Data $n$ & $\begin{array}{r}\text { MI AOD } \\
\text { mean (SD) }\end{array}$ & $\begin{array}{r}\text { DRAGON AOD } \\
\text { mean }(\mathrm{SD})\end{array}$ & $\begin{array}{l}\text { AOD } \\
\text { diff. }\end{array}$ & $R$ & Slope & $\begin{array}{r}y \text { - } \\
\text { offset }\end{array}$ & RMSE \\
\hline 1 & 400 & $0.42(0.34)$ & $0.43(0.25)$ & -0.010 & 0.942 & 1.278 & -0.13 & 0.115 \\
\hline 2 & 76 & $0.43(0.21)$ & $0.36(0.16)$ & 0.071 & 0.814 & 1.054 & 0.051 & 0.122 \\
\hline 3 & 273 & $0.51(0.39)$ & $0.55(0.31)$ & $-\mathbf{0 . 0 3 3}$ & 0.949 & 1.190 & $-\mathbf{0 . 1 3 8}$ & 0.121 \\
\hline 4 & 341 & $0.63(0.34)$ & $0.66(0.26)$ & -0.023 & 0.829 & 1.101 & -0.089 & 0.192 \\
\hline 5 & 408 & $0.52(0.37)$ & $0.70(0.36)$ & -0.172 & 0.891 & 0.915 & -0.112 & 0.167 \\
\hline 6 & 4 & $0.61(0.17)$ & $0.68(0.02)$ & -0.067 & 0.927 & 7.337 & -4.359 & 0.056 \\
\hline 7 & 109 & $0.36(0.24)$ & $0.41(0.17)$ & -0.049 & 0.859 & 1.198 & -0.130 & 0.122 \\
\hline 8 & 182 & $0.46(0.22)$ & $0.50(0.18)$ & -0.044 & 0.771 & 0.955 & -0.021 & 0.141 \\
\hline 9 & 458 & $0.56(0.35)$ & $0.55(0.26)$ & 0.004 & 0.871 & 1.164 & -0.087 & 0.169 \\
\hline 10 & 275 & $0.57(0.32)$ & $0.59(0.26)$ & -0.019 & 0.875 & 1.077 & -0.065 & 0.156 \\
\hline 11 & 108 & $0.45(0.27)$ & $0.51(0.22)$ & -0.062 & 0.782 & 0.966 & -0.045 & 0.165 \\
\hline 12 & 23 & $0.58(0.29)$ & $0.45(0.16)$ & 0.138 & 0.849 & 1.581 & -0.122 & 0.152 \\
\hline 13 & 232 & $0.67(0.47)$ & $0.68(0.37)$ & -0.012 & 0.914 & 1.154 & -0.117 & 0.190 \\
\hline 14 & 355 & $0.58(0.35)$ & $0.64(0.27)$ & -0.065 & 0.862 & 1.118 & -0.140 & 0.179 \\
\hline 15 & 430 & $0.60(0.35)$ & $0.66(0.27)$ & -0.063 & 0.846 & 1.102 & -0.130 & 0.189 \\
\hline 16 & 227 & $0.70(0.50)$ & $0.67(0.44)$ & 0.031 & 0.952 & 1.104 & -0.039 & 0.153 \\
\hline 17 & 47 & $0.49(0.31)$ & $0.54(0.21)$ & -0.047 & 0.778 & 1.111 & -0.107 & 0.190 \\
\hline 18 & 272 & $0.43(0.27)$ & $0.49(0.21)$ & -0.066 & 0.812 & 1.051 & -0.091 & 0.159 \\
\hline 19 & 56 & $0.60(0.28)$ & $0.64(0.16)$ & -0.035 & 0.776 & 1.345 & -0.254 & 0.173 \\
\hline 20 & 254 & $0.66(0.32)$ & $0.60(0.26)$ & 0.058 & 0.890 & 1.090 & 0.003 & 0.147 \\
\hline 21 & 71 & $0.41(0.21)$ & $0.42(0.18)$ & -0.009 & 0.834 & 0.987 & -0.003 & 0.117 \\
\hline 22 & 112 & $0.44(0.21)$ & $0.41(0.14)$ & 0.035 & 0.775 & 1.199 & -0.047 & 0.132 \\
\hline 23 & 206 & $0.66(0.37)$ & $0.58(0.25)$ & 0.081 & 0.892 & 1.336 & -0.114 & 0.167 \\
\hline 24 & 82 & $0.37(0.26)$ & $0.45(0.20)$ & -0.086 & 0.907 & 1.185 & -0.170 & 0.107 \\
\hline 25 & 46 & $0.30(0.21)$ & $0.42(0.16)$ & $-\mathbf{0 . 1 2 0}$ & 0.656 & 0.862 & -0.062 & 0.159 \\
\hline 26 & 69 & $0.40(0.23)$ & $0.48(0.22)$ & -0.087 & 0.858 & 0.925 & -0.050 & 0.119 \\
\hline 27 & 138 & $0.49(0.32)$ & $0.51(0.21)$ & -0.029 & 0.778 & 1.162 & -0.112 & 0.197 \\
\hline 28 & 317 & $0.48(0.29)$ & $0.55(0.25)$ & -0.063 & 0.871 & 1.006 & -0.067 & 0.143 \\
\hline 29 & 336 & $0.62(0.38)$ & $0.67(0.29)$ & -0.054 & 0.835 & 1.080 & -0.108 & 0.206 \\
\hline 30 & 246 & $0.62(0.40)$ & $0.63(0.27)$ & -0.009 & 0.868 & 1.259 & -0.171 & 0.197 \\
\hline 31 & 437 & $0.60(0.35)$ & $0.61(0.26)$ & -0.015 & 0.821 & 1.104 & -0.078 & 0.200 \\
\hline 32 & 135 & $0.50(0.27)$ & $0.35(0.17)$ & 0.144 & 0.703 & 1.152 & 0.090 & 0.194 \\
\hline 33 & 458 & $0.56(0.39)$ & $0.62(0.33)$ & -0.051 & 0.942 & 1.099 & -0.112 & 0.130 \\
\hline 34 & 290 & $0.63(0.38)$ & $0.63(0.27)$ & 0.004 & 0.913 & 1.274 & -0.169 & 0.156 \\
\hline 35 & 93 & $0.41(0.24)$ & $0.43(0.17)$ & -0.017 & 0.935 & 1.303 & -0.147 & 0.086 \\
\hline 36 & 115 & $0.43(0.29)$ & $0.51(0.20)$ & -0.087 & 0.787 & 1.140 & -0.159 & 0.178 \\
\hline 37 & 260 & $0.61(0.35)$ & $0.61(0.27)$ & -0.001 & 0.835 & 1.097 & -0.060 & 0.194 \\
\hline 38 & 92 & $0.32(0.20)$ & $0.38(0.14)$ & -0.055 & 0.804 & 1.136 & -0.107 & 0.121 \\
\hline 39 & 316 & $0.64(0.37)$ & $0.65(0.26)$ & -0.018 & 0.805 & 1.140 & -0.110 & 0.219 \\
\hline
\end{tabular}

of the regression slope. The change in correlation coefficient and RMSE was not significant.

\section{Summary}

A single-channel algorithm was used to retrieve AOD over East Asia by adopting a new aerosol model, derived from data from the mesoscale network measurement campaign deploying sun-sky radiometers, DRAGON-NE Asia 2012. The campaign was performed during MAM 2012 to improve our understanding of the AOPs on a high spatial scale over well-known aerosol source regions where aerosol loading is affected by both desert emissions and industrial pollutants. In addition, the direct solar measurements of spectral AOD undertaken during the campaign were used to improve the satellite-based aerosol retrieval algorithm by providing a data set for validation.

The accuracy of the single-channel algorithm is strongly affected by the surface reflectance estimation and the assumed aerosol model. To estimate the surface reflectance, 
Table 4. Summary statistics of the comparison between the MI AOD (550 nm) retrieved with the updated LUT and AERONET AOD $(550 \mathrm{~nm})$. The site numbers correspond to the numbers listed in Table 1 and Fig. 9a. The sites mentioned in Sect. 4.2 are represented by bold font.

\begin{tabular}{|c|c|c|c|c|c|c|c|c|}
\hline $\begin{array}{l}\text { Site } \\
\text { no. }\end{array}$ & Data $n$ & $\begin{array}{r}\text { MI AOD } \\
\text { mean (SD) }\end{array}$ & $\begin{array}{r}\text { DRAGON AOD } \\
\text { mean }(\mathrm{SD})\end{array}$ & $\begin{array}{l}\text { AOD } \\
\text { diff. }\end{array}$ & $R$ & Slope & $\begin{array}{r}y- \\
\text { offset }\end{array}$ & RMSE \\
\hline 1 & 402 & $0.39(0.32)$ & $0.43(0.25)$ & -0.033 & 0.944 & 1.205 & -0.121 & 0.107 \\
\hline 2 & 76 & $0.40(0.19)$ & $0.36(0.16)$ & 0.045 & 0.812 & 0.965 & 0.058 & 0.112 \\
\hline 3 & 284 & $0.49(0.39)$ & $0.55(0.32)$ & -0.058 & 0.949 & 1.139 & -0.134 & 0.122 \\
\hline 4 & 340 & $0.58(0.31)$ & $0.66(0.26)$ & -0.072 & 0.803 & 0.974 & -0.055 & 0.185 \\
\hline 5 & 413 & $0.50(0.35)$ & $0.69(0.36)$ & -0.195 & 0.882 & 0.856 & -0.095 & 0.164 \\
\hline 6 & 4 & $0.58(0.16)$ & $0.68(0.02)$ & -0.097 & 0.926 & 6.857 & -4.062 & 0.053 \\
\hline 7 & 108 & $0.34(0.22)$ & $0.41(0.17)$ & -0.064 & 0.853 & 1.113 & -0.110 & 0.116 \\
\hline 8 & 186 & $0.44(0.21)$ & $0.50(0.18)$ & -0.066 & 0.763 & 0.894 & -0.013 & 0.136 \\
\hline 9 & 454 & $0.51(0.32)$ & $0.55(0.26)$ & -0.038 & 0.847 & 1.036 & -0.057 & 0.167 \\
\hline 10 & 276 & $0.53(0.30)$ & $0.59(0.26)$ & -0.065 & 0.854 & 0.973 & -0.049 & 0.155 \\
\hline 11 & 111 & $0.41(0.25)$ & $0.50(0.21)$ & -0.087 & 0.775 & 0.896 & -0.035 & 0.155 \\
\hline 12 & 22 & $0.56(0.28)$ & $0.45(0.16)$ & 0.103 & 0.854 & 1.537 & -0.141 & 0.143 \\
\hline 13 & 242 & $0.62(0.44)$ & $0.68(0.37)$ & -0.056 & 0.902 & 1.073 & -0.106 & 0.190 \\
\hline 14 & 353 & $0.53(0.33)$ & $0.64(0.27)$ & -0.111 & 0.842 & 1.014 & -0.120 & 0.176 \\
\hline 15 & 431 & $0.56(0.33)$ & $0.66(0.27)$ & -0.108 & 0.830 & 1.019 & -0.120 & 0.186 \\
\hline 16 & 234 & $0.64(0.46)$ & $0.66(0.42)$ & -0.013 & 0.949 & 1.040 & -0.039 & 0.147 \\
\hline 17 & 44 & $0.43(0.24)$ & $0.52(0.21)$ & -0.088 & 0.805 & 0.928 & -0.050 & 0.139 \\
\hline 18 & 276 & $0.40(0.26)$ & $0.49(0.21)$ & -0.092 & 0.787 & 0.979 & -0.081 & 0.157 \\
\hline 19 & 56 & $0.59(0.28)$ & $0.64(0.16)$ & -0.054 & 0.745 & 1.290 & -0.240 & 0.183 \\
\hline 20 & 261 & $0.60(0.29)$ & $0.59(0.26)$ & 0.005 & 0.880 & 0.984 & 0.015 & 0.138 \\
\hline 21 & 71 & $0.38(0.20)$ & $0.42(0.18)$ & -0.036 & 0.832 & 0.919 & -0.002 & 0.111 \\
\hline 22 & 111 & $0.41(0.19)$ & $0.41(0.13)$ & 0.006 & 0.765 & 1.087 & -0.029 & 0.123 \\
\hline 23 & 208 & $0.62(0.35)$ & $0.58(0.26)$ & 0.034 & 0.885 & 1.179 & -0.070 & 0.164 \\
\hline 24 & 82 & $0.34(0.23)$ & $0.45(0.19)$ & -0.104 & 0.895 & 1.098 & -0.148 & 0.104 \\
\hline 25 & 46 & $0.29(0.20)$ & $0.42(0.16)$ & -0.134 & 0.652 & 0.802 & -0.051 & 0.150 \\
\hline 26 & 70 & $0.38(0.23)$ & $0.49(0.22)$ & -0.104 & 0.835 & 0.882 & -0.047 & 0.125 \\
\hline 27 & 137 & $0.46(0.31)$ & $0.52(0.21)$ & -0.058 & 0.774 & 1.112 & -0.116 & 0.194 \\
\hline 28 & 315 & $0.45(0.26)$ & $0.54(0.25)$ & -0.097 & 0.852 & 0.900 & -0.042 & 0.136 \\
\hline 29 & 338 & $0.57(0.36)$ & $0.67(0.29)$ & -0.098 & 0.816 & 0.997 & -0.096 & 0.206 \\
\hline 30 & 245 & $0.57(0.37)$ & $0.63(0.27)$ & -0.058 & 0.842 & 1.129 & -0.138 & 0.197 \\
\hline 31 & 440 & $0.55(0.33)$ & $0.61(0.27)$ & -0.060 & 0.798 & 0.997 & -0.058 & 0.201 \\
\hline 32 & 138 & $0.46(0.25)$ & $0.35(0.17)$ & 0.104 & 0.710 & 1.080 & 0.075 & 0.179 \\
\hline 33 & 460 & $0.53(0.37)$ & $0.61(0.33)$ & -0.080 & 0.938 & 1.042 & -0.106 & 0.128 \\
\hline 34 & 294 & $0.59(0.37)$ & $0.64(0.28)$ & -0.048 & 0.917 & 1.181 & -0.163 & 0.146 \\
\hline 35 & 93 & $0.40(0.24)$ & $0.43(0.18)$ & -0.033 & 0.936 & 1.227 & -0.132 & 0.082 \\
\hline 36 & 117 & $0.42(0.31)$ & $0.52(0.20)$ & -0.104 & 0.770 & 1.171 & -0.193 & 0.197 \\
\hline 37 & 261 & $0.56(0.33)$ & $0.61(0.27)$ & -0.051 & 0.803 & 0.977 & -0.036 & 0.194 \\
\hline 38 & 94 & $0.30(0.19)$ & $0.37(0.15)$ & -0.066 & 0.799 & 1.037 & -0.079 & 0.113 \\
\hline 39 & 318 & $0.59(0.35)$ & $0.65(0.26)$ & -0.066 & 0.786 & 1.042 & -0.093 & 0.217 \\
\hline
\end{tabular}

a minimum reflectance method was applied, and the BAOD was used to correct for the persistent background aerosol levels over East Asia. The BAOD was obtained by using the MODIS standard AOD product from 2006 to 2012. With respect to aerosol model selection, however, the single-channel algorithm was limited by a lack of spectral information. For this reason, the aerosol model was integrated from a seasonally sorted inversion data set, taking into account the monsoon climate over the region, which was used to calculate LUT. To overcome the limitations of the retrieval accuracy related to the limitation in aerosol type selection, it was important to optimize the aerosol model. The AOPs were obtained from two AERONET inversion data groups to understand the effects of assumptions in the aerosol model. The original AOPs were constructed from the inversion data set provided by 13 AERONET sites over East Asia before 2011, while the new AOPs were modified using data from an increased number of measurement sites, as well as additional data from the original sites. The obtained AOPs show that the denser deployment of measurement sites has a greater ef- 
fect on the AOPs than the extended periods of measurement in terms of refractive index. An increase in the effective radius of coarse particle distribution was also found. This increase in spatial resolution resulted in an increase of SSA by $\sim 1.1 \%$ during MAM, which was expected to lead to a decrease in AOD.

According to the sensitivity test, the error in the retrieved AOD varied from -19 to $+20 \%$, in proportion with the assumed SSA error of $\pm 3 \%$ in the aerosol model, for a scenario with a reference AOD value of 0.15 and a surface reflectance of 0.05 . The uncertainty in retrieved AOD due to the assumed SSA error was increased at greater values of AOD, and ranged between -20 and $+23 \%$ when the reference AOD value was 1.20. In short, the overestimation of SSA in the aerosol model results in the underestimation of AOD, and assumed errors in SSA have a greater effect at higher values of AOD. Considering the relationship between surface reflectance and the uncertainty, the retrieval error in real measurements could be larger than the suggested value when the surface reflectance is near the critical reflectance. In the meantime, the error in surface reflectance shows larger effects in the accuracy of low AOD than the error in SSA.

The qualitative comparison between AODs retrieved from MODIS and MI showed a reasonably high correlation. The MI AOD showed the capability to track the dust plume crossing from the Shandong peninsula to the northern Korean peninsula by taking advantage of geostationary measurements, whereas the MODIS AOD provided two AOD maps during a single day by using both Terra and Aqua. AODs retrieved with both the original and new aerosol model showed a good correlation with sun photometer data from the DRAGON-NE Asia campaign. The correlation coefficient and the RMSE were slightly changed from 0.87 to 0.85 and 0.18 to 0.17 , respectively, by applying the new aerosol model. Increased SSA values in the new aerosol model resolved problems with AOD being overestimated, and the regression slope was decreased from 1.08 to 1.00. A comparison for each campaign site also showed that the statistics of the correlation were generally improved. For some regions, however, changes in the aerosol model led to underestimation of the AOD.

As shown here, the use of a fixed aerosol model is an important issue in a single-channel algorithm. Similarly, the application of a well-defined model for each assumed aerosol type is important to obtain accurate results from a multichannel algorithm. According to a study with the GOCI multi-channel algorithm (Choi et al., 2015), however, the effects of applying the DRAGON-NE Asia data set were less significant, in other words less dependent on the assumed aerosol model. The GOCI algorithm categorizes 26 aerosol models according to the fine-mode fraction at $550 \mathrm{~nm}$ and SSA at $440 \mathrm{~nm}$, and selects an optimized aerosol type at each measured pixel and time. The accuracy of the BAOD is another important issue when using the minimum reflectance method to retrieve AOD, because overestimation of the BAOD results in a systematic underestimation of the AOD. The dense measurements of the AERONET sun photometer network can be used to optimize the BAOD at higher resolution, though the network cannot cover the whole field of view of the satellite measurements. Furthermore, an improved correction for cloud masking is required to reduce noise in the retrieval.

Acknowledgements. We thank the principal investigators and their staff for establishing and maintaining the AERONET sites used in this investigation. We also gratefully acknowledge the principal investigator and staff of the DRAGON-NE Asia campaign for their effort. This research was supported by the GEMS program of the Ministry of Environment, Korea, and the Eco Innovation Program of KEITI (2012000160002). This research was partially supported by the Brain Korea 21 Plus (J. Kim and M. Kim).

Edited by: M. Schulz

\section{References}

Bevan, S. L., North, P. R. J., Los, S. O., and Grey, W. M. F.: A global dataset of atmospheric aerosol optical depth and surface reflectance from AATSR, Remote Sens. Environ., 116, 199-210, doi:10.1016/j.rse.2011.05.024, 2012.

Castanho, A. D. D. A., Martins, J. V., and Artaxo, P.: MODIS aerosol optical depth Retrievals with high spatial resolution over an urban area using the critical reflectance, J. Geophys. Res.Atmos., 113, D02201, doi:10.1029/2007jd008751, 2008.

Choi, M., Kim, J., Lee, J., Kim, M., Je Park, Y., Jeong, U., Kim, W., Holben, B., Eck, T. F., Lim, J. H., and Song, C. K.: GOCI Yonsei Aerosol Retrieval (YAER) algorithm and validation during DRAGON-NE Asia 2012 campaign, Atmos. Meas. Tech. Discuss., 8, 9565-9609, doi:10.5194/amtd-8-9565-2015, 2015.

Deroubaix, A., Martiny, N., Chiapello, I., and Marticorena, B.: Suitability of OMI aerosol index to reflect mineral dust surface conditions: Preliminary application for studying the link with meningitis epidemics in the sahel, Remote Sens. Environ., 133, 116-127, doi:10.1016/j.rse.2013.02.009, 2013.

Dubovik, O. and King, M. D.: A flexible inversion algorithm for retrieval of aerosol optical properties from Sun and sky radiance measurements, J. Geophys. Res.-Atmos., 105, 20673-20696, doi:10.1029/2000jd900282, 2000.

Dubovik, O., Smirnov, A., Holben, B. N., King, M. D., Kaufman, Y. J., Eck, T. F., and Slutsker, I.: Accuracy assessments of aerosol optical properties retrieved from Aerosol Robotic Network (AERONET) Sun and sky radiance measurements, J. Geophys. Res.-Atmos., 105, 9791-9806, doi:10.1029/2000jd900040, 2000.

Dubovik, O., Holben, B., Eck, T. F., Smirnov, A., Kaufman, Y. J., King, M. D., Tanre, D., and Slutsker, I.: Variability of absorption and optical properties of key aerosol types observed in worldwide locations, J. Atmos. Sci., 59, 590-608, doi:10.1175/15200469(2002)059<0590:Voaaop>2.0.Co;2, 2002.

Eck, T. F., Holben, B. N., Reid, J. S., Dubovik, O., Smirnov, A., O'Neill, N. T., Slutsker, I., and Kinne, S.: Wavelength dependence of the optical depth of biomass burning, urban, and 
desert dust aerosols, J. Geophys. Res.-Atmos., 104, 3133331349, doi:10.1029/1999jd900923, 1999.

Fraser, R. S. and Kaufman, Y. J.: The relative importance of aerosol scattering and absorption in remote-sensing, IEEE T. Geosci. Remote, 23, 625-633, doi:10.1109/Tgrs.1985.289380, 1985.

Frey, R. A., Ackerman, S. A., Liu, Y. H., Strabala, K. I., Zhang, H., Key, J. R., and Wang, X. G.: Cloud detection with MODIS. Part I: Improvements in the MODIS cloud mask for collection 5, J. Atmos. Ocean. Tech., 25, 1057-1072, doi:10.1175/2008jtecha1052.1, 2008.

Grey, W. M. F., North, P. R. J., Los, S. O., and Mitchell, R. M.: Aerosol optical depth and land surface reflectance from Multiangle AATSR measurements: Global validation and intersensor comparisons, IEEE T. Geosci. Remote, 44, 2184-2197, doi:10.1109/Tgrs.2006.872079, 2006.

Holben, B. N., Eck, T. F., Slutsker, I., Tanre, D., Buis, J. P., Setzer, A., Vermote, E., Reagan, J. A., Kaufman, Y. J., Nakajima, T., Lavenu, F., Jankowiak, I., and Smirnov, A.: Aeronet - a federated instrument network and data archive for aerosol characterization, Remote Sens. Environ., 66, 1-16, doi:10.1016/S00344257(98)00031-5, 1998.

Holben, B. N., Tanre, D., Smirnov, A., Eck, T. F., Slutsker, I., Abuhassan, N., Newcomb, W. W., Schafer, J. S., Chatenet, B., Lavenu, F., Kaufman, Y. J., Castle, J. V., Setzer, A., Markham, B., Clark, D., Frouin, R., Halthore, R., Karneli, A., O’Neill, N. T., Pietras, C., Pinker, R. T., Voss, K., and Zibordi, G.: An emerging ground-based aerosol climatology: Aerosol optical depth from AERONET, J. Geophys. Res.-Atmos., 106, 12067-12097, doi:10.1029/2001jd900014, 2001.

Hsu, N. C., Tsay, S. C., King, M. D., and Herman, J. R.: Aerosol properties over bright-reflecting source regions, IEEE T. Geosci. Remote, 42, 557-569, doi:10.1109/Tgrs.2004.824067, 2004.

Huebert, B. J., Bates, T., Russell, P. B., Shi, G. Y., Kim, Y. J., Kawamura, K., Carmichael, G., and Nakajima, T.: An overview of ACE-Asia: Strategies for quantifying the relationships between Asian aerosols and their climatic impacts, J. Geophys. Res.Atmos., 108, 8633, doi:10.1029/2003JD003550, 2003.

IPCC: Climate Change 2013: The Physical Science Basis. Contribution of Working Group I to the Fifth Assessment Report of the Intergovernmental Panel on Climate Change, edited by: Stocker, T. F., Qin, D., Plattner, G.-K., Tignor, M., Allen, S. K., Boschung , J., Nauels, A., Xia, Y., Bex, V., and Midgley, P. M., Cambridge University Press, Cambridge, United Kingdom and New York, NY, USA, 1535 pp., doi:10.1017/CB O9781107415324, 2013.

Kahn, R. A., Gaitley, B. J., Garay, M. J., Diner, D. J., Eck, T. F., Smirnov, A., and Holben, B. N.: Multiangle Imaging SpectroRadiometer global aerosol product assessment by comparison with the Aerosol Robotic Network, J. Geophys. Res.-Atmos., 115, D23209, doi:10.1029/2010jd014601, 2010.

Kim, J., Lee, J., Lee, H. C., Higurashi, A., Takemura, T., and Song, C. H.: Consistency of the aerosol type classification from satellite remote sensing during the atmospheric brown cloud-east Asia regional experiment campaign, J. Geophys. Res.-Atmos., 112, D22s33, doi:10.1029/2006jd008201, 2007.

Kim, J., Yoon, J. M., Ahn, M. H., Sohn, B. J., and Lim, H. S.: Retrieving aerosol optical depth using visible and mid-IR channels from geostationary satellite MTSAT-1R, Int. J. Remote Sens., 29, 6181-6192, doi:10.1080/01431160802175553, 2008.
Kim, M., Kim, J., Lee, J., Lee, Y. G., Yoon, J. M., and Song, C. H.: Analysis of Background Aerosol using Global AERONET Sun-photometer Measurements, in preparation, 2016.

Kim, M., Kim, J., Wong, M. S., Yoon, J., Lee, J., Wu, D., Chan, P. W., Nichol, J. E., Chung, C.-Y. C., and Ou, M.-L.: Improvement of aerosol optical depth retrieval over Hong Kong from a geostationary meteorological satellite using critical reflectance with background optical depth correction, Remote Sens. Environ., 142, 176-187, 2014.

Knapp, K. R., Vonder Haar, T. H., and Kaufman, Y. J.: Aerosol optical depth retrieval from goes-8: Uncertainty study and retrieval validation over South America, J. Geophys. Res.-Atmos., 107, 4055, doi:10.1029/2001jd000505, 2002.

Knapp, K. R., Frouin, R., Kondragunta, S., and Prados, A.: Toward aerosol optical depth retrievals over land from GOES visible radiances: Determining surface reflectance, Int. J. Remote Sens., 26, 4097-4116, doi:10.1080/01431160500099329, 2005.

Kotchenova, S. Y. and Vermote, E. F.: Validation of a vector version of the $6 \mathrm{~S}$ radiative transfer code for atmospheric correction of satellite data. Part ii. Homogeneous Lambertian and anisotropic surfaces, Appl. Optics, 46, 4455-4464, doi:10.1364/Ao.46.004455, 2007.

Kotchenova, S. Y., Vermote, E. F., Matarrese, R., and Klemm, F. J.: Validation of a vector version of the $6 \mathrm{~S}$ radiative transfer code for atmospheric correction of satellite data. Part i: Path radiance, Appl. Optics, 45, 6762-6774, doi:10.1364/Ao.45.006762, 2006.

Lee, J., Kim, J., Song, C. H., Ryu, J. H., Ahn, Y. H., and Song, C. K.: Algorithm for retrieval of aerosol optical properties over the ocean from the Geostationary Ocean Color Imager, Remote Sens. Environ., 114, 1077-1088, doi:10.1016/j.rse.2009.12.021, 2010.

Lee, J., Kim, J., Yang, P., and Hsu, N. C.: Improvement of aerosol optical depth retrieval from MODIS spectral reflectance over the global ocean using new aerosol models archived from AERONET inversion data and tri-axial ellipsoidal dust database, Atmos. Chem. Phys., 12, 7087-7102, doi:10.5194/acp-12-70872012, 2012.

Levy, R. C., Remer, L. A., and Dubovik, O.: Global aerosol optical properties and application to Moderate Resolution Imaging Spectroradiometer aerosol retrieval over land, J. Geophys. Res.Atmos., 112, D13210, doi:10.1029/2006jd007815, 2007a.

Levy, R. C., Remer, L. A., Mattoo, S., Vermote, E. F., and Kaufman, Y. J.: Second-generation operational algorithm: Retrieval of aerosol properties over land from inversion of Moderate Resolution Imaging Spectroradiometer spectral reflectance, J. Geophys. Res.-Atmos., 112, D13211, doi:10.1029/2006jd007811, 2007b.

Levy, R. C., Remer, L. A., Kleidman, R. G., Mattoo, S., Ichoku, C., Kahn, R., and Eck, T. F.: Global evaluation of the Collection 5 MODIS dark-target aerosol products over land, Atmos. Chem. Phys., 10, 10399-10420, doi:10.5194/acp-10-10399-2010, 2010.

Levy, R. C., Mattoo, S., Munchak, L. A., Remer, L. A., Sayer, A. M., Patadia, F., and Hsu, N. C.: The Collection 6 MODIS aerosol products over land and ocean, Atmos. Meas. Tech., 6, 29893034, doi:10.5194/amt-6-2989-2013, 2013.

Lyapustin, A., Smirnov, A., Holben, B., Chin, M., Streets, D. G., Lu, Z., Kahn, R., Slutsker, I., Laszlo, I., Kondragunta, S., Tanre, D., Dubovik, O., Goloub, P., Chen, H. B., Sinyuk, A., Wang, Y., and Korkin, S.: Reduction of aerosol absorption in Beijing since 2007 
from MODIS and AERONET, Geophys. Res. Lett., 38, L10803, doi:10.1029/2011g1047306, 2011a.

Lyapustin, A., Wang, Y., Laszlo, I., Kahn, R., Korkin, S., Remer, L., Levy, R., and Reid, J. S.: Multiangle implementation of atmospheric correction (MAIAC): 2. Aerosol algorithm, J. Geophys. Res.-Atmos., 116, D03211, doi:10.1029/2010jd014986, 2011 b.

Nakajima, T., Yoon, S. C., Ramanathan, V., Shi, G. Y., Takemura, T., Higurashi, A., Takamura, T., Aoki, K., Sohn, B. J., Kim, S. W., Tsuruta, H., Sugimoto, N., Shimizu, A., Tanimoto, H., Sawa, Y., Lin, N. H., Lee, C. T., Goto, D., and Schutgens, N.: Overview of the Atmospheric Brown Cloud East Asian Regional Experiment 2005 and a study of the aerosol direct radiative forcing in east Asia, J. Geophys. Res.-Atmos., 112, D24s91, doi:10.1029/2007jd009009, 2007.

Park, M. E., Song, C. H., Park, R. S., Lee, J., Kim, J., Lee, S., Woo, J.-H., Carmichael, G. R., Eck, T. F., Holben, B. N., Lee, S.-S., Song, C. K., and Hong, Y. D.: New approach to monitor transboundary particulate pollution over Northeast Asia, Atmos. Chem. Phys., 14, 659-674, doi:10.5194/acp-14-659-2014, 2014.

Pope, C. A. and Dockery, D. W.: Health effects of fine particulate air pollution: Lines that connect, J. Air Waste Manage., 56, 709742, 2006

Remer, L. A., Kaufman, Y. J., Tanre, D., Mattoo, S., Chu, D. A., Martins, J. V., Li, R. R., Ichoku, C., Levy, R. C., Kleidman, R. G., Eck, T. F., Vermote, E., and Holben, B. N.: The MODIS aerosol algorithm, products, and validation, J. Atmos. Sci., 62, 947-973, doi:10.1175/Jas3385.1, 2005.

Saide, P. E., Kim, J., Song, C. H., Choi, M., Cheng, Y. F., and Carmichael, G. R.: Assimilation of next generation geostationary aerosol optical depth retrievals to improve air quality simulations, Geophys. Res. Lett., 41, 9188-9196, doi:10.1002/2014gl062089, 2014.

Sayer, A. M., Hsu, N. C., Bettenhausen, C., Jeong, M.-J., Holben, B. N., and Zhang, J.: Global and regional evaluation of overland spectral aerosol optical depth retrievals from SeaWiFS, Atmos. Meas. Tech., 5, 1761-1778, doi:10.5194/amt-5-1761-2012, 2012.

Sayer, A. M., Hsu, N. C., Eck, T. F., Smirnov, A., and Holben, B. N.: AERONET-based models of smoke-dominated aerosol near source regions and transported over oceans, and implications for satellite retrievals of aerosol optical depth, Atmos. Chem. Phys., 14, 11493-11523, doi:10.5194/acp-14-11493-2014, 2014.

Smirnov, A., Holben, B. N., Eck, T. F., Dubovik, O., and Slutsker, I.: Cloud-screening and quality control algorithms for the AERONET database, Remote Sens. Environ., 73, 337-349, doi:10.1016/S0034-4257(00)00109-7, 2000.

Taylor, K. E.: Summarizing multiple aspects of model performance in a single diagram, J. Geophys. Res.-Atmos., 106, 7183-7192, doi:10.1029/2000jd900719, 2001.

Torres, O., Tanskanen, A., Veihelmann, B., Ahn, C., Braak, R., Bhartia, P. K., Veefkind, P., and Levelt, P.: Aerosols and surface UV products from ozone monitoring instrument observations: An overview, J. Geophys. Res.-Atmos., 112, D24s47, doi:10.1029/2007jd008809, 2007.
Urm, Y. D. and Sohn, B. J.: Estimation of aerosol optical thickness over East Asia using GMS-5 visible channel measurements, J. Atmos., 15, 203-211, 2005.

Vermote, E. F., Tanre, D., Deuze, J. L., Herman, M., and Morcrette, J. J.: Second simulation of the satellite signal in the solar spectrum, 6S: An overview, IEEE T. Geosci. Remote, 35, 675-686, doi:10.1109/36.581987, 1997.

von Hoyningen-Huene, W., Yoon, J., Vountas, M., Istomina, L. G., Rohen, G., Dinter, T., Kokhanovsky, A. A., and Burrows, J. P.: Retrieval of spectral aerosol optical thickness over land using ocean color sensors MERIS and SeaWiFS, Atmos. Meas. Tech., 4, 151-171, doi:10.5194/amt-4-151-2011, 2011.

Wang, J., Christopher, S. A., Brechtel, F., Kim, J., Schmid, B., Redemann, J., Russell, P. B., Quinn, P., and Holben, B. N.: Geostationary satellite retrievals of aerosol optical thickness during ACE-Asia, J. Geophys. Res.-Atmos., 108, 8657, doi:10.1029/2003jd003580, 2003.

Waquet, F., Cairns, B., Knobelspiesse, K., Chowdhary, J., Travis, L. D., Schmid, B., and Mishchenko, M. I.: Polarimetric remote sensing of aerosols over land, J. Geophys. Res.-Atmos., 114, D01206, doi:10.1029/2008jd010619, 2009.

Wong, M. S., Lee, K. H., Nichol, J. E., and Li, Z. Q.: Retrieval of aerosol optical thickness using MODIS $500 \times 500 \mathrm{~m}(2)$, a study in Hong Kong and the pearl river delta region, IEEE T. Geosci. Remote, 48, 3318-3327, doi:10.1109/Tgrs.2010.2045124, 2010.

Yang, P., Feng, Q., Hong, G., Kattawar, G. W., Wiscombe, W. J., Mishchenko, M. I., Dubovik, O., Laszlo, I., and Sokolik, I. N.: Modeling of the scattering and radiative properties of nonspherical dust-like aerosols, J. Aerosol. Sci., 38, 995-1014, doi:10.1016/j.jaerosci.2007.07.001, 2007.

Yoon, J.-M.: Effects of atmospheric and surface properties on the retrieval of AOD from geostationary satellite, $\mathrm{PhD}$ thesis, Department of Atmospheric Scinces, Yonsei Univ, Seoul, Republic of Korea, 2006.

Yoon, J. M., Kim, J., Lee, J. H., Cho, H. K., Sohn, B. J., and Ahn, M. A.: Retrieved of aerosol optical depth over East Asia from a geostationary satellite, MTSAT-1R, Asia-Pacific J. Atmos. Sci., 43, 133-142, 2007.

Yoon, J., Burrows, J. P., Vountas, M., von Hoyningen-Huene, W., Chang, D. Y., Richter, A., and Hilboll, A.: Changes in atmospheric aerosol loading retrieved from space-based measurements during the past decade, Atmos. Chem. Phys., 14, 68816902, doi:10.5194/acp-14-6881-2014, 2014.

Zhang, H., Lyapustin, A., Wang, Y., Kondragunta, S., Laszlo, I., Ciren, P., and Hoff, R. M.: A multi-angle aerosol optical depth retrieval algorithm for geostationary satellite data over the United States, Atmos. Chem. Phys., 11, 11977-11991, doi:10.5194/acp11-11977-2011, 2011.

Zhang, J. L., Christopher, S. A., and Holben, B. N.: Intercomparison of smoke aerosol optical thickness derived from GOES 8 imager and ground-based sun photometers, J. Geophys. Res.Atmos., 106, 7387-7397, doi:10.1029/2000jd900540, 2001. 